\title{
Poly (I:C)-induced maternal immune activation modifies ventral hippocampal regulation of stress reactivity: prevention by environmental enrichment
}

\author{
Xin Zhao, Ruqayah Mohammed, Hieu Tran, Mary Erickson, Amanda C. Kentner*
}

School of Arts \& Sciences, Health Psychology Program, Massachusetts College of Pharmacy and Health Sciences, Boston Massachusetts, United States 02115

*Corresponding author:

Amanda Kentner

amanda.kentner@mcphs.edu

Office \#617-274-3360

Fax \# 617-732-2959

Keywords

Environmental programming; Maternal immune activation; Prenatal immune activation; Gestational; Poly (I:C); Poly I:C; Toll-like 3 receptors; Inflammation; Fetal programming; Maternal behavior; Maternal care; Corticosterone; Glucocorticoid receptor; Corticotropin releasing hormone receptor; Corticotropin releasing factor; Synaptic plasticity; Sex difference; Social interaction; Social approach; Social vigilance; Experience; Inflammation; Schizophrenia; Autism; Social; Hippocampus; Prefrontal cortex; Suprammamillary nucleus; Hypothalamus; Oxytocin; Vasopressin; cFos; CamkIIa, Protein Kinase 


\title{
Highlights
}

- Environmental enrichment (EE) protocols are used clinically to promote rehabilitation

- Use of EE in animal models may identify mechanisms underlying clinical successes

- Maternal immune activation (MIA) decreased social engagement; this effect was blocked by EE

- MIA reduced c-Fos activation in the dentate gyrus, while EE reduced activation in the hypothalamus, in response to social stimuli

- EE inhibited MIA-induced HPA dysregulation in ventral hippocampus

\begin{abstract}
Environmental enrichment (EE) has been successfully implemented in human rehabilitation settings. However, the mechanisms underlying its success are not understood. Incorporating components of EE protocols into our animal models allows for the exploration of these mechanisms and their role in mitigation. Using a mouse model of maternal immune activation (MIA), the present study explored disruptions in social behavior and associated hypothalamic pituitary adrenal (HPA) axis functioning, and whether a supportive environment could prevent these effects. We show that prenatal immune activation of tolllike receptor 3 , by the viral mimetic polyinosinic-polycytidylic acid (poly(I:C)), led to disrupted maternal care in that dams built poorer quality nests, an effect corrected by EE housing. Standard housed male and female MIA mice engaged in higher rates of repetitive rearing and had lower levels of social interaction, alongside sex-specific expression of several ventral hippocampal neural stress markers. Moreover, MIA males had delayed recovery of plasma corticosterone in response to a novel social encounter. Enrichment housing, likely mediated by improved maternal care, protected against these MIA-induced effects. We also evaluated $c$-Fos immunoreactivity associated with the novel social experience and found MIA to decrease neural activation in the dentate gyrus. Activation in the hypothalamus was blunted in EE housed animals, suggesting that the putative circuits modulating social behaviors may be different between standard and complex housing environments. These data demonstrate that augmentation of the environment supports parental care and offspring safety/security, which can offset effects of early health adversity by buffering HPA axis dysregulation. Our findings provide further evidence for the viability of EE interventions in maternal and pediatric settings.
\end{abstract}




\section{Introduction}

Pregnancy is a vital period for offspring brain development and the trajectory of this growth may be impacted by disruptions in maternal health. Human epidemiological research has revealed an association between infection during gestation and risk for neurodevelopmental disorders (Babulas et al., 2006; Estes and McAllister, 2016; Sørensen et al., 2008). With the outbreak and worldwide spread of coronavirus disease 2019 (COVID-19), the long-lasting risks that gestational infections pose to offspring has gained significant attention (Cavalcante et al., 2020). It is critical to understand the underlying pathogenic mechanisms associated with these infections, and potential therapeutic interventions.

In preclinical research, rodent models of maternal immune activation (MIA) have been widely used to investigate biological mechanisms that underlie behavioral and cognitive abnormalities relevant to psychopathology (Estes and McAllister, 2016; Kentner et al., 2019a; Knuesel et al., 2014; Bauman \& Van de Water, 2020). For example, a mid-gestational injection of the viral mimetic polyinosinic:polycytidylic acid (poly (I:C)), a commercially available synthetic analog of double-stranded RNA, can induce an extensive collection of innate immune responses (Mueller et al., 2019) and lead to a wide array of abnormalities in brain morphology ( $\mathrm{Li}$ et al., 2009; Meyer et al., 2006) as well as neurochemical and pharmacological reactions (Zuckerman et al., 2003; Zuckerman and Weiner, 2005) associated with altered behaviors and cognitive abilities (Li et al., 2014; Ozawa et al., 2006). Despite the abovementioned progress in unravelling the disruptive effects of MIA, we still have limited understanding of how gestational immune insults alter the neurobiological substrates that underlie the behavioral abnormalities relevant to psychopathology, and more importantly, the potential for protective strategies against MIA-induced neurodevelopmental abnormalities.

At the neural level, the ventral hippocampus is a potentially important region for mediating MIA's disruptive effects on social interaction, anxiety, and physiological responses to stress. The ventral hippocampus is an anatomically heterogeneous brain region that demonstrates remarkable plasticity (Fanselow and Dong, 2010). This region has been implicated in modulating social interactions (Bagot et al., 2015; Felix-Ortiz and Tye, 2014), anxiety-like behaviors, and regulation of the stress response (Gulyaeva, 2019; McEwen et al., 2016). In anxiogenic environments, increased neural activity of the ventral, but not dorsal, hippocampus is associated with elevated displays of anxiety-related behaviors (Adhikari et al., 2010,2011 ). This association is mediated, at least partially, by synchronized neural activity between the ventral hippocampus and the prefrontal cortex (PFC), to promote anxiety-related behaviors (Adhikari et al., 2010, 2011; Padilla-Coreano et al., 2016). Previous work has demonstrated disruptive effects of MIA on several aspects of hippocampal anatomy and functioning, including decreased levels of glucocorticoid receptors and glutamate (Connors et al., 2014), altered glutamate decarboxylase expression (Dickerson et al., 2014) and lower glucose uptake (Hadar et al., 2015). Together, this work implicates the ventral hippocampus as an important brain site for mediating MIA's disruptive effects on social behaviors and stress responses.

One characteristic of MIA's effects is that many phenotypic abnormalities are not fully developed until late in adolescence or early adulthood (Ozawa et al., 2006; Piontkewitz et al., 2011; Zuckerman et al., 2003), which gives a time window for the application of potential therapeutic interventions. However, there has been relatively little evaluation on how supportive measures may protect the brain and behavior (Kentner et al., 2019b; Luby et al., 2020). Environmental enrichment (EE) is a non-invasive and non-pharmacological therapy characterized by exposure to novel environments with rich social, motor, cognitive and sensory stimulation. Growing evidence has shown that exposure to an enriched environment can enhance brain plasticity (e.g., increased dendritic branching, synaptogenesis, 
neurogenesis etc; Brenes et al., 2016; Kolb et al., 1998; Van Praag et al., 2000), the turnover of several neurotransmitters (Escorihuela et al., 1995; Hilario et al., 2016), as well as improvement in cognitive functions (Williams et al., 2001; Zeleznikow-Johnston et al., 2017). In humans, EE has been used to reverse behavioral and cognitive impairments associated with stroke, cerebral palsy, and autism (Aronoff et al., 2016; de Brito Brandã et al., 2019; Janssen et al., 2014; Morgan et al., 2014; Morgan et al., 2015; Rosbergen et al., 2017; Woo et al., 2015). Using animal models of health and disease to explore these benefits of EE provide insight into the underlying biological mechanisms of its successes and limitations.

In the animal laboratory, Van Dellen et al., (2000) were the first to demonstrate that living in spatially complex environments (i.e., EE) delayed the appearance of neurological symptoms of Huntington's disease, and thereafter EE has been shown to improve brain pathology in animal models of Alzheimer's disease and major depression (Chourbaji et al., 2011; Herring et al., 2009). A previous study using a poly (I:C) mouse model found that MIA interfered with the supportive effects of post-weaning EE (Buschert et al., 2016). However, this study employed male CD-1 mice that become aggressive when housed in EE (McQuaid et al., 2012; McQuaid et al., 2013; McQuaid et al., 2018). The experience of unstable social hierarchies' and territorial aggression (e.g., fighting for resources/EE devices) likely created a negative, as opposed to enriching, environment.

Our lab has previously used rat models of prenatal lipopolysaccharide (LPS) administration to assess the beneficial effects of EE (Connors et al., 2014; Kentner et al., 2016; Kentner et al., 2018a; Núñez Estevez et al., 2020; Zhao et al., 2020) and its beneficial effects may be mediated through its interaction with maternal care, which impacts offspring development via nursing behaviors and nutritional provisioning, in addition to temperature regulation (Francis and Meaney, 1999; Connors et al., 2015). Although previous studies on the protective effects of $\mathrm{EE}$ revealed ambiguous findings regarding maternal nursing behaviors (e.g., licking, grooming, and crouching; Begenisic et al., 2015; Cutuli et al., 2015; de Jong et al., 1998; Li et al., 2016; Sale et al., 2004; Strzelewicz et al., 2019; Welberg et al., 2006; Zuena et al., 2016), enriched dams generally showed better nest-building quality (Cutuli et al., 2015). In contrast to EE's positive effects, gestational treatment with poly (I:C) led to deficient maternal care behaviors (Ronovsky et al., 2017; Schwendener et al., 2009). Collectively, prior research lends some support to the idea that EE may interact with parental care to offset effects of early health adversities by buffering hypothalamic pituitary adrenal (HPA) axis dysregulation. Indeed, when used in pediatric clinical settings, the benefits of EE are mediated at least in part by caregiver engagement (Aronoff et al., 2016; Bowman \& Evans, 2019; de Brito Brandão et al., 2019; Morgan et al., 2014; Morgan et al., 2015; Woo et al., 2015).

Building upon our previous work in rats, the current study aimed to examine if the protective effects of EE on social behavior and HPA axis regulation extends to toll-like 3 receptor activation by using a poly (I:C)-induced MIA model in mice. Importantly, we used C57BL/6J mice, which are a less aggressive strain; they did not demonstrate evidence of increased fighting in response to higher cage densities and competition for resources (Nicholson et al., 2009), suggesting that EE is appropriate for these animals.

\section{Materials and methods}

\subsection{Animals and housing}

C57BL/6J mice were acquired from the Jackson Laboratory (Bar Harbor, ME), and housed at $20^{\circ} \mathrm{C}$ on a $12 \mathrm{~h}$ light/dark cycle (0700-1900 light) with ad libitum access to food 
and water. A schematic timeline of experimental procedures is presented in Figure. 1A. Female mice were housed in pairs in one of two conditions: environmental enrichment (EE; N40HT mouse cage, Ancare, Bellmore, NY; see Figure. 1B), comprised of a larger cage and access to toys, tubes, a Nylabone, Nestlets ${ }^{\circledR}$ (Ancare, Bellmore, NY) and Bed-r' Nest ${ }^{\circledR}$ (ScottPharma Solutions, Marlborough MA), or standard cages (SD; N10HT mouse cage, Ancare, Bellmore, NY; see Figure. 1C) with Nestlets ${ }^{\circledR}$ and a Nylabone only. Male animals were paired in SD conditions unless they were breeding, at which point they were housed with two females in EE or SD cages. Immediately after breeding, dams were placed into clean cages, maintaining their assigned housing conditions.

On the morning of gestational day $(\mathrm{G}) 12$, pregnant dams were randomly allocated to receive a $20 \mathrm{mg} / \mathrm{kg}$ intraperitoneal injection of polyinosine-polycytidylic acid (poly (I:C); tlrlpicw, lot number PIW-41-03, InvivoGen), or vehicle (sterile pyrogen-free $0.9 \% \mathrm{NaCl}$ ). Twenty-four hours later, maternal body weights were recorded to validate the poly (I:C) challenge by either slowed weight gain or loss. To ensure the safety of the pups, toys and Nylabones ${ }^{\circledR}$ were removed on G19 and returned after maternal nest quality evaluations on P15. To maintain standardized litter sizes, some pups were fostered to same age and group matched dams. Additional methodological details can be found in the reporting table from Kentner et al. (2019a), provided as Supplementary Table S1. Animal procedures were approved by the MCPHS University Institutional Animal Care and Use Committee and carried out in compliance with the recommendations outlined by the Guide for the Care and Use of Laboratory Animals of the National Institutes of Health.

\subsection{Nest building quality}

While there are some inconsistencies in the literature, some investigators find that gestational poly (I:C) alters parental care quality (e.g., licking/grooming, nursing, time off nest) (Weber-Stadlbauer et al., 2020; Ronovsky et al., 2017; Schwendener et al., 2009). Enriched environments are also known to change patterns of maternal behavior in rats, and in some cases seem to make dams more efficient in their care duties (Baldini et al, 2013; Connors et al., 2015; Strzelewicz et al., 2019; Welberg et al., 2006). Extensive maternal care observations are difficult with our mouse model as the dams tend to build closed domeshaped nests, hiding their pups and obscuring maternal-pup interactions. Therefore, we conducted passive maternal nest quality observations on P15. This was done 24 hours after litters were placed into a fresh cage and each dam provided four fresh Nestlets ${ }^{\circledR}$ (Ancare, Bellmore, NY). Nest quality was scored on a 5-point Likert scale, adapted from Gerfen et al., (2006) in which $0=$ no nest; $1=$ flat nest; $2=$ a slightly cupped shape but less than $1 / 2$ of a dome shape; $3=$ taller than $1 / 2$ of a dome shape, but not fully enclosed and $4=$ fully enclosed nest/dome. We also recorded the number of unused Nestlets ${ }^{\circledR}$.

\subsection{Offspring behavior}

Offspring were weaned into same-sex groups on P21 and maintained in their housing assignments until behavioral tests commenced $(\mathrm{SD}=2-3$ animals/cage; $\mathrm{EE}=4-5$ animals/cage). Supplementary Table S2 outlines the litters and treatment groups for the study. On P70, one male and one female from each litter was habituated to an open field arena $(40 \mathrm{~cm} \times 40 \mathrm{~cm} \times 28 \mathrm{~cm}$ ) for three-minutes (Duque-Wilckens et al., 2020; Williams et al., 2020). Behavior was recorded and videos scored via an automated behavioral monitoring software program (Cleversys TopScan, Reston, VA) for percent time spent in the center of the arena and total distance traveled $(\mathrm{mm})$. Rearing and grooming behaviors were evaluated using the same procedures as the social tests described below. All equipment was thoroughly 
cleaned with Quatriside TB between each animal and test. Immediately after the open field habituation period, two cleaned wire containment cups were placed on opposite ends of the arena for the five-minute social preference test. One cup contained a novel untreated adult mouse of the same sex, age, and strain and the other cup contained a novel object. Placement of novel mice and objects was interchanged between trials. A mouse was actively investigating when its nose was directed within $2 \mathrm{~cm}$ of a containment cup or it was touching the cup. For each animal, a social preference index was calculated by the formula ([time spent with the mouse] / [time spent with the inanimate object + time spent with the mouse]) $\square-0.5$ (Scarborough et al., 2020).

To determine neuronal activation associated with a social experience, animals were reintroduced to the open field arena on P85, but this time only one wire cup containing an unfamiliar mouse of the same sex, age, and strain was presented. Duration of time animals spent actively investigating the novel mouse was evaluated across the 10-minute social exposure period. We also assessed time spent in the interaction zone and vigilance behavior during the first three-minutes of the social exposure (adapted from Duque-Wilckens et al., 2020; Williams et al., 2020). Briefly, social interaction was defined as the time animals spent within $8 \mathrm{~cm}$ (interaction zone) of the novel mouse. A mouse was demonstrating social vigilance when its head was oriented towards the novel mouse when outside of the interaction zone. Blinded observers evaluated all social behavior videos for the frequency of rearing behavior and duration of grooming and social behaviors using a manual behavioral scoring software program (ODLogTM 2.0, http://www.macropodsoftware.com/). Inter-rater reliability was determined by Pearson $r$ correlation to be $0.860-0.900$ for each manually scored behavior.

\subsection{Tissue collection and analysis}

Ninety minutes after the P85 social investigation exposure, brains were collected for $c$-Fos immunohistochemistry and qPCR analyses. A mixture of Ketamine/Xylazine $(150 \mathrm{mg} / \mathrm{kg}$, i.p/15 mg/kg, i.p) was used to anesthetize animals. Blood was collected via cardiac puncture and placed into an ethylenediaminetetraacetic acid (EDTA)-coated microtainer tube (Becton Dickson, Franklin Lakes New Jersey). Samples were centrifuged at 1000 relative centrifugal force (rcf) for $10 \mathrm{~min}$ for plasma separation. Animals were perfused intracardially with a chilled phosphate buffer solution. Prefrontal cortex, hippocampus, and hypothalamus were dissected from the left hemisphere. Samples were frozen on dry ice and stored at $-75^{\circ} \mathrm{C}$ until processing. The right hemisphere was post-fixed in a $4 \%$ paraformaldehyde, phosphate buffer $0.1 \mathrm{M}$ solution (BM-698, Boston BioProducts) overnight at $4^{\circ} \mathrm{C}$. Tissue was then submerged in ice cold $10 \%$ sucrose in PBS (with $0.1 \%$ sodium azide) and incubated at $4^{\circ} \mathrm{C}$ overnight. The following day, solution was replaced with $30 \%$ sucrose in PBS for 3 days. Tissue was rapidly flash frozen with 2-methylbutane (O3551-4, Fisher Scientific) and stored at $-75^{\circ} \mathrm{C}$ until sectioning.

\subsection{Corticosterone assay}

Plasma samples were evaluated with a corticosterone ELISA kit (\#ADI-900-097, Enzo Life Sciences, Farmingdale, NY). The small sample assay protocol was followed, as recommended by the manufacturer, and each sample was processed in duplicate. The minimum detectable concentration was $26.99 \mathrm{pg} / \mathrm{ml}$, and the intra- and inter-assay coefficients of variation were $6.6 \%$ and $7.8 \%$, respectively.

\section{6. $R T-P C R$}


Total RNA was extracted from frozen tissue using the RNeasy Lipid Tissue Mini Kit (Qiagen, 74804) and resuspended in RNase-free water. Isolated RNA was quantified utilizing a NanoDrop 2000 spectrophotometer (ThermoFisher Scientific). According to the manufacturer's protocol, total RNA was reverse transcribed to cDNA with the Transcriptor High Fidelity cDNA Synthesis Kit (\#5081963001, Millipore Sigma) and the final cDNA solution was stored at $-20^{\circ} \mathrm{C}$ for analysis. Quantitative real-time PCR with Taqman ${ }^{\mathrm{TM}}$ Fast Advanced Master Mix (\#4444963, Applied Biosystems) was used to measure the mRNA expression of corticotropin releasing hormone (Crh, Mm01293920_s1), Crh receptor 1 (Crhr1, Mm00432670_m1), glucocorticoid receptor (Nr3c1, Mm00433832_m1), oxytocin (Oxt, Mm00726655_s1), oxytocin receptor (Oxytr, Mm01182684_m1), vasopressin receptor (Avpr1a, Mm00444092_m1x), calcium/calmodulin dependent protein kinase II alpha (Camk2a, Mm00437967_m1), and protein kinase C alpha (Prkca, Mm00440858_m1). All reactions were analyzed in triplicate using optical 96-well plates (Applied Biosystems StepOnePlus ${ }^{\mathrm{TM}}$ Real-Time PCR System) and relative gene expression levels were evaluated using the $2^{-} \Delta \Delta^{\mathrm{CT}}$ method with 18S (Hs99999901_s1). This housekeeping gene was selected as it was not affected by MIA or housing condition. Gene expression was normalized in relation to $18 \mathrm{~S}$ and data presented as mean expression relative to same sex SD-saline treated controls.

\subsection{Immunohistochemistry}

Coronal sections (40 um thick) were obtained on a cryostat (Leica CM1860) as a 1:4 series and stored at $-20^{\circ} \mathrm{C}$ in cryoprotectant until immunocytochemistry. Free-floating sections were washed in PBS to remove the cryoprotectant prior to incubation in rabbit anticFos primary antibody (1:5000; ABE457, Millipore Sigma) for one hour at room temperature (RT) and 48 hours at $4^{\circ} \mathrm{C}$. Tissue was then washed in PBS and incubated in goat anti-rabbit IgG biotinylated secondary antibody (1:600) for one hour at RT. Tissue was washed in PBS and incubated in $\mathrm{A} / \mathrm{B}$ solution (A and B solutions of the Vectastain ${ }^{\circledR}$ Elite ABC-HRP Kit, \#PK-6161, Vector Laboratories) for one hour at RT. This was followed by another PBS wash after which tissue was briefly washed in $0.175 \mathrm{M}$ sodium acetate and incubated with 3,3'Diaminobenzidine tetrahydrochloride (Ni-DAB; \#D5905-50TAB, Millipore Sigma). Sections were then washed briefly with $0.05 \mathrm{M}$ sodium acetate and PBS and stored at $4^{\circ} \mathrm{C}$ in PBS until mounting. Tissue was mounted in $0.85 \%$ saline and slides air-dried for 48 hours before being dehydrated in an alcohol dilution series, cleared in xylene, and cover slipped with DPX (\#06522-100ML, Millipore Sigma). Slides were imaged on a Keyence Microscope [BZ-X800, Keyence] and the number of Fos-immunoreactive cells in each region of interest was counted by two experimenters blind to experimental treatments during counting. Inter-rater reliability was determined by Pearson $r$ correlation to be $0.830-0.990$ for each brain region evaluated. The area of each selected region was measured with NIH ImageJ software (Schneider et al., 2012) to determine the number of stained cells per square millimeter. Prelimbic and infralimbic regions of the medial prefrontal cortex were identified using the Allen Mouse Brain Atlas (image 36), as were regions of the ventral hippocampus (e.g., vCA1, CA2, vCA3, dentate gyrus), the supramammillary nucleus ( $\mathrm{SuM}$ ) and whole hypothalamus (image 81 ).

\subsection{Statistical analysis}

Statistics were performed using the software package Statistical Software for the Social Sciences (SPSS) version 26.0 (IBM, Armonk, NY). The assumption of normality was evaluated with the Shapiro-Wilk test and Kruskal-Wallis tests (expressed as $X^{2}$ ) employed in 
rare cases of significantly skewed data. Maternal body weights were evaluated using repeated measures 2-way ANOVA (MIA $\times$ housing). Since qPCR data were normalized to same sex controls, a 2-way ANOVA (MIA $\times$ housing) was conducted for each gene of interest in each sex separately. The remaining measures were evaluated with 3-way ANOVAs (sex $\times$ MIA $\times$ housing). Pearson correlations were analyzed between the P85 social measures versus ventral hippocampal Fos -immunoreactivity and gene expression. LSD post hocs were applied except where there were fewer than three levels, in which case pairwise t-tests and Levene's (applied in the occurrence of unequal variances) were utilized. The False Discovery Rate (FDR) was applied to correct for multiple testing procedures in all gene expression and correlation experiments. All data are graphically expressed as mean \pm SEM. If there were no significant sex differences, data were collapsed together for visualization. The partial eta-squared $\left(n_{p}{ }^{2}\right)$ is also reported as an index of effect size for the ANOVAs (the range of values being $0.02=$ small effect, $0.13=$ moderate effect, 0.26 = large effect; Miles and Shevlin, 2001).

\section{Results}

3.1. MIA challenge interferes with maternal body weight gain and nesting behaviors while EE supports maternal care quality

To validate the integrity of our MIA model, we evaluated maternal body weight gain following gestational poly (I:C) challenge. While baseline weight gain was comparable across conditions ( $\mathrm{p}>0.05$ ), dams treated with poly (I:C) had considerably slower body weight gain compared to saline $(\mathrm{p}=0.001$; Figure 1D) 24 hours after challenge (time $x$ MIA: $\left.\mathrm{F}(1,46)=27.433, \mathrm{p}=0.001, n_{p}{ }^{2}=0.374\right)$. This provides evidence that our poly $(\mathrm{I}: \mathrm{C})$ administration protocol induced an immune response (Kentner et al., 2019a).

On P14, dams were given four Nestlets ${ }^{\circledR}$ and nest construction quality evaluated 24 hours later. There were no differences across treatments in terms of the number of nesting resources used ( $p>0.05$; data not shown). However, SD-poly (I:C) dams constructed nests of significantly poorer quality compared to SD-saline $\left(X^{2}(1)=6.378, p=0.012\right.$ ) and EE-poly (I:C) mice $\left(X^{2}(1)=7.84, p=0.005\right.$; Figure 1E). There were no differences between EE-saline and EE-poly (I:C) nest quality ( $p>0.05)$, highlighting the protective effects of enhanced environments on parental care.

\subsection{Environmental enrichment blocks prenatal poly (I:C) induced reductions in social motivation and associated displays of repetitive behavior}

While there is a strong focus on identifying the negative consequences and mechanisms of MIA on the developing brain and behavior, very little attention is directed towards the prevention or rehabilitation of these effects in laboratory animal studies (Kentner et al., 2019b). Given EE's protective effects in the LPS-indued MIA model (Nunez et al., 2020; Connors et al., 2014), we determined whether this protection extended to the poly (I:C) model of MIA. As expected, P70 social preference was significantly reduced by poly (I:C)induced MIA in both SD males (Figure 2A) and females (Figure 2B; MIA $x$ housing: $\mathrm{F}(1,83$ ) $\left.=7.047, \mathrm{p}=0.010, n_{p}{ }^{2}=0.078\right)$. This effect was completely blocked by enriched housing (SDsaline vs SD-poly (I:C): p $=0.005$; SD-poly (I:C) vs EE-poly (I:C): p $=0.0001$; Figure 2AC).

To determine whether the effect of MIA on social interest was reflective of an increased anxiety-like phenotype, we evaluated behaviors in the P70 open field test. During this assessment it was apparent that only housing condition $\left(\mathrm{F}(1,83)=4.024, \mathrm{p}=0.048, n_{p}{ }^{2}=\right.$ 0.049 ) impacted the percentage of time spent in the center of the arena (EE: $32.69 \pm 1.36 \mathrm{vs}$ SD 29 $\pm 1.39 ; p=0.028$; Figure 2D). Distance traveled was not affected by any treatment condition ( $>0.05$; Figure 2E). Male animals reared more frequently than females $(p<0.05$; 
Supplementary Figures S1A,B; P70 main effect of sex: $\mathrm{F}(1,83)=5.518, \mathrm{p}=0.021, n_{p}{ }^{2}=$ 0.062 ; P85 main effect of sex: $\left.\mathrm{F}(1,81)=4.436, \mathrm{p}=0.038, \mathrm{n}_{\mathrm{p}}{ }^{2}=0.051\right)$ and female EE mice groomed more than SD females $(\mathrm{p}=0.0001$; Supplementary Figures S1C,D; sex $x$ housing: $\left.\mathrm{F}(1,81)=4.352, \mathrm{p}=0.040, n_{p}{ }^{2}=0.050\right)$ in the open field test, but there was no effect of MIA on these measures. EE animals tend to display higher levels of body licking behavior as they habituate more quickly to novel environments (Rojas-Carvajal et al., 2018). Here, EE-saline mice groomed longer during the social preference test, an effect that was blunted by MIA (EE-saline vs EE-poly $(I: C): X^{2}(1)=7.899, \mathrm{p}=0.005$; Figure 2F). However, there were no group differences in grooming during the P85 social investigation test $(\mathrm{p}>0.05$; Supplementary Figure S1E).

In contrast, during the P70 social preference test, male and female SD-poly (I:C) mice showed a higher frequency of rearing behaviors compared to same-sex SD-saline $(p=0.024)$ and EE-poly (I:C) mice ( $\mathrm{p}=0.006$; Figure 2G; MIA $x$ housing: $\mathrm{F}(1,83)=4.313, \mathrm{p}=0.035, \mathrm{p}$ $\left.=0.035, n_{p}{ }^{2}=0.054\right)$.

To more fully characterize the heightened stress response/delayed stress recovery associated with MIA, we exposed animals to a social stimulus on P85 to correlate behavior with $c$-Fos activation and gene expression ninety minutes later. Male SD-poly (I:C) mice spent less time directly engaging with the novel mouse compared to SD-saline males $(\mathrm{p}=$ $0.010)$ across the 10 minute test period ( $\operatorname{sex} x$ MIA: $\left(\mathrm{F}(1,81)=9.209, \mathrm{p}=0.003, n_{p}{ }^{2}=0.102\right.$; MIA x housing: $\mathrm{F}(1,81)=5.546, \mathrm{p}=0.012, n_{p}{ }^{2}=0.075$; Figure $\left.2 \mathbf{H}, \mathbf{I}\right)$. As expected, male and female EE animals spent more time in direct social contact compared to SD mice $(p=0.001)$, blocking the attenuating effect of poly (I:C) on social behavior. Patterns of poly (I:C) impeding male social interest $(p=0.002)$, and EE increasing social interest $(p=0.0001)$, were again confirmed by the respective reduced and elevated times spent within the interaction zone (sex $x$ MIA $x$ housing: $\mathrm{F}(1,81)=11.162, \mathrm{p}=0.001, n_{p}{ }^{2}=0.120$; Figure $\mathbf{2 J}, \mathbf{K})$. While social vigilance was not directly impacted by MIA ( $>>0.05)$, it was significantly reduced by $\mathrm{EE}$ housing $\left(S D: 4.96 \pm 1.16\right.$ vs $E E: 3.10 \pm 0.46 ; X^{2}(1)=4.171, \mathrm{p}=$ 0.041; Figure 2L), which may account for higher instances of social contact from these animals.

\subsection{MIA reduced c-Fos activation in the dentate gyrus of male and female offspring}

Ninety minutes following the P85 social exposure, we evaluated $c$-Fos activation throughout brain regions critical to anxiety-like and social behavior (Ko, 2017; Chen et al., 2020; Walsh et al., 2020; Figure 3A,B). There were no main effects or interactions with respect to sex, so male and female data were collapsed and visualized together. Although $c$ Fos activation in the medial prefrontal cortex (prelimbic and infralimbic regions; Figure 3C) and hippocampal CA1, CA2, and CA3 regions were not affected ( $p>0.05$; Figure 3D), in the hippocampus MIA significantly decreased the number of $c$-Fos immunoreactive cells expressed in the dentate gyrus (DG; $X^{2}(1)=4.001, \mathrm{p}=0.0 .045 ;$ MIA $: \mathrm{x} \square=97.35 \pm 12.68 \mathrm{vs}$ Saline: $\mathrm{x} \square=174.91 \pm 31.98$; Figure 3D). The DG is important for the mediation of odor and reward processing, in addition to social recognition and social avoidance (Kesner et al., 2018; Kheirbek et al., 2013; Weeden et a., 2015).

\subsection{Environmental enrichment housing remodels neuronal activation patterns associated} with a novel social experience

Neurons in the supramammillary nucleus $(\mathrm{SuM})$ are activated during novel social interactions (Chen et al., 2020). Specifically, contextual novelty reportedly activates the SuM-dentate gyrus circuit and social novelty activates a SuM-CA2 circuit (Chen et al., 2020; Walsh et al., 2020). This led us to evaluate c-Fos immunoreactivity in this hypothalamic region following MIA. While evaluation of the SuM revealed a significant MIA by housing 
interaction $\left(\mathrm{F}(1,50)=4.098, \mathrm{p}=0.048, n_{p}{ }^{2}=0.076\right.$; Figure 3E), follow-up tests were not significant. However, housing significantly affected $c$-Fos activation in the hypothalamus (including the SuM region; $X^{2}(1)=4.137, p=0.042$; Figure 3E) during the P85 social exposure. The lower neural activation of $\mathrm{EE}$ animals $(\mathrm{x} \square=133.87 \pm 20.25)$ in this region may be indicative of their faster habituation rates compared to SD ( $\mathrm{x} \square=214.23 \pm 29.64$; RojasCarvajal et al., 2018). Figure $\mathbf{3 F}$ shows representative samples of $c$-Fos staining for each experimental group.

Pearson's correlations confirmed that direct social investigation of the novel mouse on P85 was positively associated with elevated $c$-Fos immunoreactivity in the hypothalamus of standard housed animals $(r=0.429, p=0.025$; Figure 3G); this effect was blunted in EE mice ( $\mathrm{p}>0.05$; Figure 3G).

Hypothalamic $c$-Fos activity was not correlated with time spent in the interaction zone, or social vigilance $(\mathrm{p}>0.05)$, highlighting the specificity of this activation. During the P85 social exposure, neural activation in the hypothalamus (including the $\mathrm{SuM}$ ) was strongly and positively correlated with vCA1 $(r=0.734, p=0.0001)$, CA2 $(r=0.703, p=0.0001)$, vCA3 $(\mathrm{r}=0.736, \mathrm{p}=0.0001)$, and DG $(\mathrm{r}=0.725, \mathrm{p}=0.0001)$ in SD animals. However, these putative circuit associations were lost with a more complex EE housing condition ( $\mathrm{p}>0.05)$. A priori tests of MIA and housing interactions among these associations again demonstrated strong positive correlations between hypothalamus + SuM with regions vCA1, CA2, vCA3 and DG in SD-saline housed mice ( $\mathrm{p}<0$. 05; Figure 3H) during the P85 social exposure. Most of these associations were maintained with MIA treatment in SD animals (Figure 3I), except for the relationship with the DG which was lost $(p>0.05)$. Interestingly, EE housing disrupted many of the associations observed in SD animals (Figure 3J,K). This may be an important consideration when trying to understand complex neural circuits using simplistic environmental conditions (Kentner et al., 2018c).

\subsection{MIA-induced dysregulation of stress associated markers in the ventral hippocampus is} antagonized by environmental enrichment

Following the P85 social exposure, several mRNA expression patterns emerged throughout the brain as a function of MIA. While there was no treatment effect on hippocampal expression of Oxt mRNA ( $p>0.05$; Supplementary Table S3), Oxtr was elevated in SD-poly (I:C) males $(\mathrm{p}=0.003)$ and lowered in SD-poly $(\mathrm{I}: \mathrm{C})$ females $(\mathrm{p}=0.029)$ compared to their respective same-sex SD-saline and poly (I:C) enriched counterparts (males: $\left(\mathrm{F}(1,28)=6.383, \mathrm{p}=0.017, n_{p}{ }^{2}=0.186\right)$; females: $\left(\mathrm{F}(1,28)=7.912 \mathrm{p}=0.009, n_{p}{ }^{2}=0.220\right.$; Figure 4A,B).

Male $\left(\mathrm{F}(1,28)=25.143, \mathrm{p}=0.001, n_{p}{ }^{2}=0.473\right.$; Figure 4C) and female hippocampal Crh $\left(\mathrm{F}(1,28)=5.673, \mathrm{p}=0.024, n_{p}{ }^{2}=0.168\right.$; Figure 4D) was also associated with significant MIA by housing effects. Specifically, SD-poly (I:C) mice had elevated levels of Crh compared to SD-saline (males: $\mathrm{p}=0.001$ ) and EE-poly $(\mathrm{I}: \mathrm{C})$ animals (males: $\mathrm{p}=0.003$; females: $\mathrm{p}=0.0001)$. Male EE-saline mice had higher Crh compared to SD-saline $(\mathrm{p}=0.003)$ and EE-poly $(\mathrm{I}: \mathrm{C})$ animals $(\mathrm{p}=0.016)$ as well. Notably, SD-poly $(\mathrm{I}: \mathrm{C})$ males also had enhanced expression of Crhr1 in the ventral hippocampus (SD-saline: $\mathrm{p}=0.001$; EE-poly $(I: C): \mathrm{p}=0.001)$, while EE-saline animals did not ( $\mathrm{p}>0.05 ;$ MIA $x$ housing: $\mathrm{F}(1,28)=8.512$, $\mathrm{p}=0.007, n_{p}{ }^{2}=0.233$; Figure 4E,F). Similar patterns of sex-specific expression associated with MIA were observed for hippocampal Nr3c1 (male MIA $x$ housing: $\mathrm{F}(1,28)=46.319$, $\mathrm{p}$ $=0.0001, n_{p}{ }^{2}=0.623$ ); females: $\mathrm{p}>0.05$; Figure 4G,H), Prkca (male MIA by housing: $\mathrm{F}(1$, $28)=35.560, \mathrm{p}=0.0001, n_{p}{ }^{2}=0.559$; female MIA $x$ housing: $\mathrm{F}(1,28)=7.153, \mathrm{p}=0.01^{\prime} n_{p}{ }^{2}=$ 0.203; Supplementary Table S3), and Camk2a (male MIA $x$ housing: $\mathrm{F}(1,28)=5.685, \mathrm{p}=$ 0.024, $n_{p}{ }^{2}=0.169$; females: $\mathrm{p}>0.05$; Supplementary Table S3). Overall, these data suggest that male SD-poly (I:C) animals are either demonstrating a heightened acute stress response 
and/or impaired ability to cope and recover from stress. Moreover, these effects can be blocked by enrichment housing. Additional sex, MIA and housing effects were revealed for the expression of genes in the prefrontal cortex, ventral hippocampus, and hypothalamus which can be found in Supplementary Table S3.

3.6. Glucocorticoid associated recovery following a social stress exposure is delayed in MIA offspring

Elevated plasma corticosterone level is one indicator of an active stress response (McEwen et al., 2015). Ninety minutes following the social stress exposure, male SD-poly (I:C) mice still demonstrated elevated levels of this steroid hormone compared to SD-saline $(\mathrm{p}=0.0001)$ and EE-poly (I:C) animals $\left(\mathrm{p}=0.008 ; \mathrm{F}(1,55)=8.781, \mathrm{p}=0.004,{ }^{2}{ }^{2}=0.138\right.$; Figure 4I,J), indicative of delayed stress recovery in these mice. While enrichment housing was associated with lower plasma corticosterone in poly (I:C) treated males, EE-saline males had elevated levels of this steroid hormone (SD-saline: $\mathrm{p}=0.001$; EE-poly: 0.019$)$ and hippocampal Nr3c1 (SD-saline: $\mathrm{p}=0.0001$; EE-poly: 0.0001; Figure 4G).

\subsection{Ventral hippocampal gene expression is sex-dependently associated with P85 social investigation}

Direct social investigation of the novel mouse was associated with sex-specific ventral hippocampal gene expression, supporting a role for these genes in our social behavior measures. Specifically, higher levels of Nr3c1, Crhr1, CamK2a (males), Oxt and Crh (females) were associated with lower social exploration levels (Figure 4K-O). Reduced time spent in the interaction zone was similarly associated with higher levels of genes in this region (males: Nr3c1, Crh, Crhr1, Camk2a, Prkca; females: Oxt; (Figure 4P-T). In contrast, heightened social vigilance was correlated with higher expression of several stress-associated gene markers in the ventral hippocampus (males: Nr3c1, Crh; females: Nr3c1, Camk2a, Oxytr; Figure 4U-Y).

\section{Discussion}

In the current study, we demonstrate that poly (I:C)-induced MIA imposes sex-specific disruptions on a variety of physiological and behavioral indices. Importantly, EE housing buffered many of these MIA effects, as reflected by more regulated displays of affiliative behaviors and a reduction in repetitive actions. Moreover, MIA associated elevations in plasma corticosterone, and several hippocampal mRNA markers indicative of HPA axis dysregulation, were dampened by the environmental intervention. Our results underscore the hippocampus as a region mediating MIA's disruptive effects and as a target for interventions such as EE. We also observed MIA to impair maternal nest building quality, which was prevented by EE housing. This suggests that parental care may be an important mediator of EE's benefits. Altogether, these data highlight the role of MIA in the behavioral expression and alteration of neural activities and markers associated with stress responses (Estes and McAllister, 2016; Knuesel et al., 2014). Moreover, our findings identify underlying mechanisms that support $\mathrm{EE}$ as a protective strategy against MIA-induced neurodevelopmental abnormalities.

\section{The Effects of MIA and EE on Maternal Nesting Behavior}

Maternal immune activation not only affects offspring behavior, but the parental behavior of the dam as well. The poor nest quality displayed by our MIA mothers echoes previous observations on the consequences of gestational immune insult (Aubert et al., 1997). Quality 
nest building is critical for maintaining pup thermoregulation (Weber and Olsson, 2008). Deterioration of the nest impacts its internal temperature, which may affect the HPA-axis development of offspring (Jans and Woodside, 1990). MIA exposed dams also spend more time building their nest, and this trait can be transmitted to following generations (Berger et al., 2018; Ronovsky et al., 2017). Our data showing poorer nest quality adds to these findings and together suggests that poly (I:C) treated mothers may be less efficient or skilled in maternal care overall.

Supportive EE interventions can help buffer the effects of MIA on maternal nest building behavior. The mechanisms underlying the disrupted nest building performance remains unclear as nest-building is a complex behavior that requires fraying, pulling, sorting, and fluffing of nest materials (Gaskill et al., 2012). Changes in motivation or motor ability for any of these behaviors can impact nest building quality. In addition to MIA, other stressors experienced prenatally such as scrapie infection (Cunningham et al., 2003), or heat and restraint (Kinsley and Svare, 1988), have also impaired nest-building behaviors. This suggests that reductions in nest quality were precipitated by stress. Therefore, the protective effects of EE on nest building are likely mediated, at least in part, by enhancing parental stress resilience (Crofton et al., 2015; Lehmann and Herkenham, 2011). Prior to the nest quality evaluation, EE dams had been provided with additional nesting materials (i.e., Bed-rRest discs + Nestlets $($ ). This supplemental support may have primed EE-poly (I:C) dams to be more responsive to the materials available to them during the nest construction test. Indeed, a previous report showed that extra naturalistic nesting materials prompted mice to construct complex dome-shaped nests, similar to those in the wild (Hess et al., 2008) and what we tended to see in our SD-saline and EE dams here.

\section{The Effects of MIA and EE on Offspring Social Behavior}

MIA exposed mice demonstrated evidence of social aversion which was buffered by EE housing. In line with previous evidence (Choi et al., 2016; Hsiao et al., 2012; Hsiao et al., 2013; Scarborough et al., 2020; Schwartzer et al., 2013; Smith et al., 2007), prenatal poly (I:C) injection on gestational day 12.5 reduced social preference for a novel same-sex individual. We speculate that for our MIA-treated SD animals, interactions with novel mice were experienced as a stressor rather than as an appetitive experience. Consistent with this interpretation, many of our SD-poly (I:C) animals had negative social preference scores suggesting that, in addition to disrupted social motivation, these animals had increased levels of social aversion as well. This notion is further supported by data of MIA mice engaging in higher rates of unsupported rearing behaviors during the social preference test.

Unsupported rearing is a type of risk assessment behavior displayed when confronted with threatening stimuli (Blanchard et al., 2011; Blanchard and Blanchard, 1989). Stressful experiences also promote the expression of this behavior (Sturman et al., 2018). Together, the reduced social preference and the enhanced display of social aversion and rearing are indicative of heightened stress reactivity in SD-poly (I:C) mice. As we have found previously with the LPS-MIA model in rats (Connors et al., 2014; Núñez Estevez et al., 2020; Zhao et al., 2020) life-long EE housing prevented reductions in social interaction and seemed to attenuate activation of the stress response.

\section{The Effects of MIA on Hippocampal Activity and the Display of Social Behavior}

MIA may also impair approach-avoidance conflict decision-making, implicating the hippocampus in disrupted social interactions. The decision to approach or to avoid a novel social stimulus is likely the net result of multiple (conflicting) motives including the motivation to approach an appetitive stimulus and the motivation to avoid a potential threat (Brodkin et al., 2004; Elliot and Covington, 2001). Aberrant approach/avoidance processes 
are linked to autism, depression, and anxiety disorders (Heuer et al., 2007; Pfaff and Barbas, 2019; Radke et al., 2014). In an anxiety-provoking condition, SD-poly (I:C) mice may be less efficient at solving approach-avoidance decision-making conflicts. This notion is supported by our finding of diminished $c$-Fos immunoreactivity in the dentate gyrus, a region implicated in the regulation of approach-avoidance behaviors under innately anxiogenic and stressful conditions (Kheirbek et al., 2013; Weeden et al., 2015). However, data are inconsistent regarding the direction of dentate gyrus' effects on approach behaviors (Kheirbek et al., 2013; Weeden et al., 2015). Although the specific role of the dentate gyrus is beyond the scope of the current study, our results suggest that reduced dentate gyrus activity may contribute to the impaired social preference in SD-MIA mice. While EE housing did not prevent this reduced neural activity following the social exposure, its beneficial effects appear to be mediated through other mechanisms more specific to HPA axis regulation.

\section{The Effects of MIA and EE on Hippocampal Feedback Regulation of the HPA Axis}

In general, MIA appears to disrupt the hippocampal feedback regulation of the HPA axis, particularly in males, leading to delayed stress recovery following social stressor exposure. This is supported by the ventral hippocampal mRNA expression data showing higher levels of Crh in both male and female SD-poly (I:C) mice, 90 minutes following stress, compared to the SD-saline controls. Also, $\mathrm{CRH}$ and glucocorticoid receptors (Crhr1 and $\mathrm{Nr} 3 \mathrm{c} 1$ ), as well as plasma corticosterone, were elevated in SD-poly (I:C) males, underscoring the sex-specific nature of this HPA axis dysregulation, despite the shared behavioral phenotypes. The occurrence of males and females displaying similar behavioral phenotypes regulated through separate sex-specific mechanisms is not unique (see Sorge et al., 2015). Additionally, there are well known sex differences that underlie the function of the stress axis. For example, sex differences in Crhr1 receptor binding may account for differences in receptor number and distribution (Kokras et al., 2019). It is likely that the HPA axis is driving some of the behavioral phenotypes that follow MIA, at least in part, but the female biomarkers only sometimes align with males due to the sex differences that underlie these mechanisms.

In addition to sex differences, there are also housing differences in HPA axis regulation. While EE attenuated many of the hippocampal gene expression changes that accompanied MIA, curiously, Crh expression and plasma corticosterone was elevated in EE-saline mice. This could be indicative of the 'double edged sword' of EE, in that for some male animals, it may be aversive (McQuaid et al., 2012; McQuaid et al., 2013). Especially with male CD-1 mice, EE can induce fighting depending on the enrichment devices used. However, in our C57BL/6J strain we did not observe physical indicators of distress or fighting among animals. One consideration is that we did not measure $\mathrm{Crhr} 2$, and the relative expression of these receptors, alongside Crhr1 (Skelton et al., 2000; Muller et al., 2003; Bale \& Vale, 2004; Greetfeld et al., 2009; Wang et al., 2012), may be responsible for the more regulated social interactions and stressor responses demonstrated by EE-saline mice. Indeed, in our previous work we have shown EE housing to decrease the relative Crhr1/Crhr2 expression in the brain (Kentner et al., 2018c). Moreover, receptor expression and engagement with their ligands are what underlie neurophysiological and behavioral phenotypes.

Overall, it is unclear whether EE-saline males were displaying indicators of a disrupted stress recovery. However, elevated hippocampal glucocorticoid receptor expression (Vivinetto et al., 2013) and baseline corticosterone (Konkle et al., 2010; Moncek et al., 2004) have been reported in EE housed animals previously; the latter hypothesized as a potential indicator for eustress (Selye, 1956; Konkle et al., 2010). It is possible that poly (I:C) impeded these effects through separate mechanisms. However, given the protection of the social behavior phenotypes, it could be that EE overcompensated against the effects of MIA. Since 
EE-saline mice did not demonstrate behavioral impairments we do not believe that the elevated HPA activity in these animals are indicative of pathogenic processes.

\section{Novel Sex-Specific Effects of MIA on the Oxytocin System in the Ventral Hippocampus}

The antistress effects of oxytocin in the hippocampus (Matsuchita et al., 2019) are altered by MIA challenge. In this study we observed elevations of hippocampal Oxtr in MIA males. A similar effect was observed in adult male rats that underwent prenatal restraint stress; these animals displayed an anxious/depressive phenotype, alongside reductions in the duration of social interactions and depolarization-evoked glutamate release in the ventral hippocampus (Mairesse et al., 2015). Other work has also shown early-life stress to alter the development of hippocampal oxytocin receptors (Noonan et al., 1994). Moreover, chronic stress and corticosterone implants increase oxytocin receptor binding in the ventral hippocampus (Liberzon and Young, 1997). However, the specific roles of increased oxytocin receptor binding remain unclear.

To our knowledge, this is the first study revealing effects of MIA and EE on the ventral hippocampal oxytocin system in females. Notably, there are significant sex differences in oxytocin receptor binding throughout forebrain regions of the brain that correlate with social interest (Dumais et al., 2013). Indeed, upregulation of Oxtr mRNA in area CA1 of the female hippocampus is hypothesized to increase social interest (Quiñones-Jenab, 1997; Dumais et al., 2013). Here, we observed reduced hippocampal Oxtr and social interest in our SD-poly (I:C) female mice, an effect rescued by EE. Overall, our results suggest opposite effects on Oxtr expression in male and female despite both sexes demonstrating similar social phenotypes. This again suggests that females are vulnerable to MIA challenges, but their impairments are at least in part mediated through separate mechanisms from males (Núñez Estevez et al., 2020).

\section{Conclusions}

\section{The Protective Potential of Supportive Interventions}

The current study demonstrates that the disruptive effects of MIA on social behaviors are associated with HPA axis dysregulation in the ventral hippocampus. The protective effects of EE reported here are consistent with our previous studies showing that EE can rescue MIAimpaired social behaviors induced by LPS (Connors et al., 2014; Kentner et al., 2016; Kentner et al., 2018b; Núñez Estevez et al., 2020; Zhao et al., 2020). Life-long EE may serve as an intervention to rescue these deficits by its ability to dampen activity of the HPA axis. When interpreting these findings, it is important to note that the validation of our model was done by evaluating maternal body weight gain following poly (I:C) challenge. The lack of maternal cytokine data to accompany this validation protocol is a limitation of this work. Additionally, it is difficult to isolate the critical timing of EE exposure that produced the beneficial effects reported in this study, and whether they are due to enhanced parental care during the early neonatal period. This is because EE removal induces depression-like behaviors and decreases the peak glucocorticoid response to acute stress (Smith et al., 2017). It should be noted that EE did not buffer all the MIA-induced changes in brain and behavior, but its success does appear to be most potent against social impairments and neural indicators of stress dysregulation.

Given the translational applications of EE as an intervention for humans (Janssen et al., 2014; Morgan et al., 2014; Rosbergen et al., 2017; Woo et al., 2015), our findings shed light on the sex-specific neural mechanisms that underlie its therapeutic success. Importantly, this work provides evidence for EE to be a viable supportive intervention against MIA in clinical settings, to be used alone or in combination with other treatments as appropriate. 


\section{Funding and Disclosure}

This project was funded by NIMH under Award Number R15MH114035 (to ACK) and the MCPHS Center for Undergraduate Research Mini-Grants (to RM \& HT). The authors wish to thank Ryland Roderick and Madeline Puracchio for technical support during the early phases of this study. The authors would also like to thank the MCPHS University School of Pharmacy and School of Arts \& Sciences for their continual support. The content is solely the responsibility of the authors and does not necessarily represent the official views of any of the financial supporters.

\section{Author Contributions}

X.Z., R.M., H.T., M.E., \& A.C.K., ran the experiments; X.Z., \& A.C.K. analyzed and interpreted the data, and wrote the manuscript; A.C.K., designed, supervised the study, and made the figures.

\section{Declaration of Competing Interest}

The authors declare that they have no known competing financial interests or personal relationships that could have appeared to influence the work reported in this paper.

\section{Figure Captions}

Figure 1. Experimental Timeline and Maternal Measures. (A) Flow chart of experiment procedures. Pictures of the (B) environmental enrichment and (C) standard housing conditions. (D) Maternal body weight differences (grams) between gestational days (G) 11 to 12 and days 12 to 13 , and (E) postnatal day 15 nest quality scores following maternal immune activation (MIA) and environmental enrichment housing. Data are expressed as mean \pm SEM, $\mathrm{n}=12-14$ dams per MIA and housing group. $* \mathrm{p}<0.05, * * \mathrm{p}<0.01$, ***p $<0.001$, versus SD-saline; \#p < 0.05, \#\#p < 0.01, \#\#\# <0.001, versus EE-poly (I:C).

Figure 2. The effects of maternal immune activation (MIA) and environmental enrichment on adult offspring social behavior. (A-G) Represent data from the postnatal day (P) 70 social preference test. Social preference index for (A) male, (B) female and (C) both sexes combined. (D) Percent of time in the center and (E) distance traveled ( $\mathrm{mm})$ in the open field test for male and female offspring. (F) The duration (seconds) of time spent grooming and (G) the number of rears. (H-L) Represent data from the P85 social investigation test. The duration of time (seconds) spent directly investigating a novel conspecific for $(\mathbf{H})$ male and (I) female offspring. Time that (J) males and (K) females spent in the interaction zone during the social investigation experience. (L) Time that male and female mice spent in social vigilance. Data are expressed as mean \pm SEM, $n=9-13$ litters represented per sex, MIA, and housing group. $* p<0.05$, **p $<0.01$, ***p $<0.001$, versus

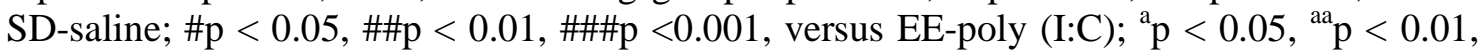
${ }^{\text {aaa }} \mathrm{p}<0.001$, main effect of housing.

Figure 3. Central c-Fos activation following a postnatal day (P) 85 social exposure in male and female offspring exposed to maternal immune activation (MIA) and environmental enrichment (EE). (A) Coronal section of the medial prefrontal cortex, including prelimbic (PL) and infralimbic (IL) regions. (B) Coronal section of the hippocampus and hypothalamus including CA1, CA2, CA3, dentate gyrus (DG), the supramammillary nucleus (SuM) and 
whole hypothalamus. Mean $c$-Fos $\left(\right.$ per $\mathrm{mm}^{2}$ ) in the $(\mathbf{C})$ medial prefrontal cortex PL and IL regions, (D) hippocampus (CA1, CA2, CA3, DG), and (E) SuM and whole hypothalamus following a ten-minute exposure to a novel social conspecific. (F) Representative images of $c$-Fos immunostaining in the dentate gyrus (top) and hypothalamus, including SuM (bottom) of standard housed (SD)-saline, SD-poly (I:C), EE-saline and EE-poly (I:C) male and female offspring. Scale bar equals $200 \mu \mathrm{m}$. (G) Pearson correlations of $c$-Fos activation and time (seconds) spent in direct social investigation, for SD (top) and EE (bottom) mice. Correlated neural activity patterns computed from Pearson's bivariate correlations of $c$-Fos positive cells between the hypothalamus (including $\mathrm{SuM}$ ) and hippocampal regions for (H) SD-saline, (I) SD-poly (I:C), (J) EE-saline, and (K) EE- poly (I:C) mice. Mean \pm SEM. There were no significant sex differences so male and female data were collapsed together; $n=13-17$ total per group. ${ }^{\mathrm{a}} \mathrm{p}<0.05,{ }^{\mathrm{aa}} \mathrm{p}<0.01$, main effect of housing; ${ }^{\mathrm{b}} \mathrm{p}<0.05,{ }^{\mathrm{bb}} \mathrm{p}<0.01$, main effect of MIA; $* \mathrm{p}<0.05, * * \mathrm{p}<0.01$, significant Pearson's correlations

Figure 4. Ventral hippocampal gene expression following maternal immune activation (MIA) and environmental enrichment housing. Male and female offspring levels of (A,B) Oxtr, (C,D) Crh, (E, F) Crhr1, (G, H) and Nr3c1 expressed as relative mRNA expression and (I, J) plasma corticosterone. Pearson correlations of ventral hippocampal relative mRNA expression and time (seconds) spent in (K-O) direct social investigation, (P-T) the interaction zone, and (U-Y) social vigilance on postnatal day 85. Gene expression data are expressed as Mean \pm SEM, $n=8$ litters represented per sex, MIA, and housing group. ${ }^{*} \mathrm{p}<0.05,{ }^{*} \mathrm{p}<0.01$, $* * * \mathrm{p}<0.001$, versus SD-saline; \#p < 0.05, \#\#p < 0.01, \#\#\# <0.001, versus EE-poly (I:C).

\section{References}

Adhikari, A., Topiwala, M.A., Gordon, J.A., 2010. Synchronized activity between the ventral hippocampus and the medial prefrontal cortex during anxiety. Neuron 65, 257-269.

Adhikari, A., Topiwala, M.A., Gordon, J.A., 2011. Single units in the medial prefrontal cortex with anxiety-related firing patterns are preferentially influenced by ventral hippocampal activity. Neuron 71, 898-910

Allen Institute for Brain Science., 2011. Allen Mouse Brain Atlas. Available from http://mouse.brain-map.org/static/atlas.

Amodeo, D., A., Lai, C-Y., Hassan, O., Mukamel, E.A., Behrens, M.M., Powell, S.B., 2019. Maternal immune activation impairs cognitive flexibility and alters transcription in frontal cortex. Nerobiol. Dis., 125, 211-218.

Aronoff, E., Hillyer, R., Leon, M., 2016. Environmental enrichment therpay for autism: outcomes with increased access. Neural Plast., 2016, 2734915.

Aspé-Sánchez, M., Moreno, M., Rivera, M.I., Rossi, A., Ewer, J., 2016. Oxytocin and vasopressin receptor gene polymorphisms: role in social and psychiatric traits.

Front. Neurosci. 9, 510.

Aubert, A., Goodall, G., Dantzer, R., Gheusi, G., 1997. Differential effects of lipopolysaccharide on pup retrieving and nest building in lactating mice. Brain Behav. Immun. 11, 107-118. 
Babulas, V., Factor-Litvak, P., Goetz, R., Schaefer, C.A., Brown, A.S., 2006. Prenatal exposure to maternal genital and reproductive infections and adult schizophrenia. Am. J. Psychiatry 163, 927-929.

Bagot, R.C., Parise, E.M., Pena, C.J., Zhang, H.-X., Maze, I., Chaudhury, D., Persaud, B., Cachope, R., Bolanos-Guzmán, C.A., Cheer, J.F., 2015. Ventral hippocampal afferents to the nucleus accumbens regulate susceptibility to depression. Nat. Commun. 6, 1-9.

Bale, T.L., Contarino, A., Smith, G.W., Chan, R., Gold, L.H., Sawchenko, P.E., Koob, G.F., Vale, W.W., Lee, K.-F., 2000. Mice deficient for corticotropin-releasing hormone receptor-2 display anxiety-like behaviour and are hypersensitive to stress. Nat. Genet. 24, 410-414.

Bale TL, Vale WW., 2004. CRF and CRF receptors: role in stress responsivity and other behaviors. Annu Rev Pharmacol Toxicol 44, 525-557.

Baldini, S., Restani, L., Baroncelli, L., Coltelli, M., Franco, R., Cenni, M.C., Maffei, L., Berardi, N., 2013. Enriched early life experiences reduce adult anxiety-like behavior in rats: a role for insulin-like growth factor 1. J. Neurosci. 33, 11715-11723.

Bannerman, D., Grubb, M., Deacon, R., Yee, B., Feldon, J., Rawlins, J., 2003. Ventral hippocampal lesions affect anxiety but not spatial learning. Behav. Brain Res. 139, 197-213.

Bauman, M.D., Murai, T., Hogrefe, C.E., Platt, M.L., 2018. Opportunities and challenges for intranasal oxytocin treatment studies in nonhuman primates. Am J Primatol., 80, e22913.

Bauman, M.D., Van de Water, J., 2020. Translational opportunities in the prenatal immune environment: promises and limitations of the maternal immune activation model. Neurobiol Dis. $141,104864$.

Begenisic, T., Sansevero, G., Baroncelli, L., Cioni, G., Sale, A., 2015. Early environmental therapy rescues brain development in a mouse model of Down syndrome. Neurobiol Dis. 82, 409-419.

Berger, S., Ronovsky, M., Horvath, O., Berger, A., Pollak, D.D., 2018. Impact of maternal immune activation on maternal care behavior, offspring emotionality and intergenerational transmission in $\mathrm{C} 3 \mathrm{H} / \mathrm{He}$ mice. Brain Behav. Immun. 70, 131-140.

Blanchard, D.C., Griebel, G., Pobbe, R., Blanchard, R.J., 2011. Risk assessment as an evolved threat detection and analysis process. Neurosci. Biobehav. Rev. 35, 991-998.

Blanchard, R.J., Blanchard, D.C., 1989. Antipredator defensive behaviors in a visible burrow system. J. Comp. Psychol. 103, 70.

Bowman, S., Evans, C., 2019. It's not just me. Parent's perceptions of a multidisciplinary therapy group for infants with disabilities. Phys. Occup. Ther. Pediatr. 39, 502-513.

Brenes, J.C., Lackinger, M., Höglinger, G.U., Schratt, G., Schwarting, R.K., Wöhr, M., 2016. Differential effects of social and physical environmental enrichment on brain plasticity, cognition, and ultrasonic communication in rats. J. Comp. Neurol. 524, 1586-1607. 
Buschert, J., Sakalem, M.E., Saffari, R., Hohoff, C., Rothermundt, M., Arolt, V., Zhang, W., Ambrée, O., 2016. Prenatal immune activation in mice blocks the effects of environmental enrichment on exploratory behavior and microglia density. Prog. Neuro-Psychopharmacol. Biol. Psychiatry 67, 10-20.

Brodkin, E.S., Hagemann, A., Nemetski, S.M., Silver, L.M., 2004. Social approachavoidance behavior of inbred mouse strains towards DBA/2 mice. Brain Res. 1002, 151-157.

Cavalcante, M.B., Cavalcante, C.T.d.M.B., Sarno, M., Barini, R., Kwak-Kim, J., 2020. Maternal immune responses and obstetrical outcomes of pregnant women with COVID-19 and possible health risks of offspring. J. Reprod. Immunol., 103250.

Chen, S., He, L., Huang, A.J.Y., Boehringer, R., Robert, V., Wintzer, M.E., Polygalov, D., Weltemier, A.Z., Tao, Y., Gu, M., Middleton, S.J., Namlkl, K., Hama, H., Therreau, L., Chevalereyre, V., Hlokl, H., Miyawakl, A., Plskorowskl, R.A., McHugh, T.J. A hypothalamic novelty signal modulates hippocampal memory. Nature, 586, 270-279.

Choi, G.B., Yim, Y.S., Wong, H., Kim, S., Kim, H., Kim, S.V., Hoeffer, C.A., Littman, D.R., Huh, J.R., 2016. The maternal interleukin-17a pathway in mice promotes autism-like phenotypes in offspring. Science 351, 933-939.

Chourbaji, S., Brandwein, C., Gass, P., 2011. Altering BDNF expression by genetics and/or environment: impact for emotional and depression-like behaviour in laboratory mice. Neurosci. Biobehav. Rev. 35, 599-611

Connors, E., Shaik, A., Migliore, M., Kentner, A.C., 2014. Environmental enrichment mitigates the sex-specific effects of gestational inflammation on social engagement and the hypothalamic pituitary adrenal axis-feedback system. Brain Behav. Immun. 42, 178-190.

Connors, E.J., Migliore, M.M., Pillsbury, S.L., Shaik, A.N., Kentner, A.C., 2015. Environmental enrichment models a naturalistic form of maternal separation and shapes the anxiety response patterns of offspring. Psychoneuroendocrinology 52, 153-167. doi: 10.1016/j.psyneuen.2014.10.021.

Crofton, E.J., Zhang, Y., Green, T.A., 2015. Inoculation stress hypothesis of environmental enrichment. Neurosci. Biobehav. Rev. 49, 19-31.

Cunningham, C., Deacon, R., Wells, H., Boche, D., Waters, S., Diniz, C.P., Scott, H., Rawlins, J., Perry, V., 2003. Synaptic changes characterize early behavioural signs in the ME7 model of murine prion disease. Eur. J. Neurosci. 17, 2147-2155

Cutuli, D., Caporali, P., Gelfo, F., Angelucci, F., Laricchiuta, D., Foti, F., De Bartolo, P., Bisicchia, E., Molinari, M., Farioli Vecchioli, S., 2015. Pre-reproductive maternal enrichment influences rat maternal care and offspring developmental trajectories: behavioral performances and neuroplasticity correlates. Front. Behav. Neurosci. 9, 66.

de Brito Brandão, M., de Costa Pinheiro Frota, L.M., Miranda, J.L., Cavalcante Brasil, R.M., Mancini, M.C., 2019. Family-centered early intervention program for Brazilian infants with congenital Zika virus syndrome: a pilot study. Phy. Occup. Ther. Pediatr., 39, 642-654. 
de Jong, I.C., Ekkel, E.D., van de Burgwal, J.A., Lambooij, E., Korte, S.M., Ruis, M.A., Koolhaas, J.M., Blokhuis, H.J., 1998. Effects of strawbedding on physiological responses to stressors and behavior in growing pigs. Physiol. Behav. 64, 303-310.

Dickerson, D., Overeem, K., Wolff, A.R., Williams, J., Abraham, W., Bilkey, D., 2014. Association of aberrant neural synchrony and altered GAD67 expression following exposure to maternal immune activation, a risk factor for schizophrenia. Transl. Psychiatry 4, e418e418.

Duarte-Guterman, P., Lieblich, S.E., Qiu, W., Splinter, J.E., Go, K.A., Casanueva-Reimon, L., Galea, L.A., 2020. Oxytocin has sex-specific effects on social behaviour and hypothalamic oxytocin immunoreactive cells but not hippocampal neurogenesis in adult rats. Horm. Behav. 122, 104734.

Dumais, K.M., Kulkarni, P.P., Ferris, C.F., Veenema, A.H., 2017. Sex differences in neural activation following different routes of oxytocin administration in awake adult rats. Psychoneuroendocrinology 81, 52-62.

Dumais, K.M., Bredewold, R., Mayer, T.E., Veenema, A., 2013. Sex differences in oxytocin receptor binding in forebrain regions: correlations with social interest in brain region- and sex-specific ways. Horm. Behav., 64, 693-701.

Duque-Wilckens N, Torres LY, Yokoyama S, Minie VA, Tran AM, Petkova SP, Hao R, Ramos-Maciel S, Rios RA, Jackson K, Flores-Ramirez FJ, Garcia-Carachure I, Pesavento PA, Iñiguez SD, Grinevich V, Trainor BC., 2020. Extrahypothalamic oxytocin neurons drive stress-induced social vigilance and avoidance. Proc Natl Acad Sci U S A. 2020 Oct 5:202011890. doi: 10.1073/pnas.2011890117.

Elliot, A.J., Covington, M.V., 2001. Approach and avoidance motivation. Educ. Psychol. Rev. 13, 73-92.

Engelmann, M., Landgraf, R., Wotjak, C.T., 2004. The hypothalamic-neurohypophysial system regulates the hypothalamic-pituitary-adrenal axis under stress: an old concept revisited. Front Neuroendocrinol. 25, 132-149.

Escorihuela, R.M., Fernandezteruel, A., Tobena, A., Vivas, N.M., Marmol, F., Badia, A., Dierssen, M., 1995. Early environmental stimulation produces long-lasting changes on $\beta$ adrenoceptor transduction system. Neurobiol. Learn. Mem. 64, 49-57.

Estes, M.L., McAllister, A.K., 2016. Maternal immune activation: Implications for neuropsychiatric disorders. Science 353, 772-777.

Fanselow, M.S., Dong, H.-W., 2010. Are the dorsal and ventral hippocampus functionally distinct structures? Neuron 65, 7-19.

Felix-Ortiz, A.C., Tye, K.M., 2014. Amygdala inputs to the ventral hippocampus bidirectionally modulate social behavior. J. Neurosci. 34, 586-595.

Francis, D.D., Meaney, M.J., 1999. Maternal care and the development of stress responses. Curr. Opin. Neurobiol. 9, 128-134. 
Gaskill, B.N., Gordon, C.J., Pajor, E.A., Lucas, J.R., Davis, J.K., Garner, J.P., 2012. Heat or insulation: behavioral titration of mouse preference for warmth or access to a nest. PloS one 7, e32799.

Gerfen, C.R., Crawley, J.N., Rogawski, M.A., Sibley, D.R., Skolnick, P., Wray, S., 2006. Short Protocols in Neuroscience: Systems and Behavioral Methods. Somerset, John Wiley \& Sons.

Greetfeld M, Schmidt MV, Sterlemann GV, Liebl C, Mu“ ller MB., 2009 A single episode of restraint stress regulates central corticotrophin-releasing hormone receptor expression and binding in specific areas of the mouse brain. J Endocrinol 21:473-480.

Gulyaeva, N.V., 2019. Functional neurochemistry of the ventral and dorsal hippocampus: stress, depression, dementia and remote hippocampal damage. Neurochem. Res. 44, 13061322 .

Hadar, R., Soto-Montenegro, M.L., Götz, T., Wieske, F., Sohr, R., Desco, M., Hamani, C., Weiner, I., Pascau, J., Winter, C., 2015. Using a maternal immune stimulation model of schizophrenia to study behavioral and neurobiological alterations over the developmental course. Schizophr. Res. 166, 238-247.

Herman, J., Dolgas, C., Carlson, S., 1998. Ventral subiculum regulates hypothalamopituitary-adrenocortical and behavioural responses to cognitive stressors. Neuroscience 86, 449-459.

Herman, J.P., Cullinan, W.E., Morano, M.I., Akil, H., Watson, S.J., 1995. Contribution of the ventral subiculum to inhibitory regulation of the hypothalamo $\square$ pituitary $\square$ adrenocortical axis. J. Neuroendocrinol. 7, 475-482.

Herman, J.P., Ostrander, M.M., Mueller, N.K., Figueiredo, H., 2005. Limbic system mechanisms of stress regulation: hypothalamo-pituitary-adrenocortical axis. Prog. NeuroPsychopharmacol. Biol. Psychiatry 29, 1201-1213.

Herring, A., Ambrée, O., Tomm, M., Habermann, H., Sachser, N., Paulus, W., Keyvani, K., 2009. Environmental enrichment enhances cellular plasticity in transgenic mice with Alzheimer-like pathology. Exp. Neurol. 216, 184-192.

Hess, S.E., Rohr, S., Dufour, B.D., Gaskill, B.N., Pajor, E.A., Garner, J.P., 2008. Home improvement: C57BL/6J mice given more naturalistic nesting materials build better nests. J. Am. Assoc. Lab. Anim. Sci., 47, 25-31.

Heuer, K., Rinck, M., Becker, E.S., 2007. Avoidance of emotional facial expressions in social anxiety: The approach-avoidance task. Behav. Res. Ther. 45, 2990-3001.

Hilario, W.F., Herlinger, A.L., Areal, L.B., de Moraes, L.S., Ferreira, T.A.A., Andrade, T.E.S.,

Martins-Silva, C., Pires, R.G.W., 2016. Cholinergic and dopaminergic alterations in nigrostriatal neurons are involved in environmental enrichment motor protection in a mouse model of Parkinson's disease. J. Mol. Neurosci. 60, 453-464. 
Hsiao, E.Y., McBride, S.W., Chow, J., Mazmanian, S.K., Patterson, P.H., 2012. Modeling an autism risk factor in mice leads to permanent immune dysregulation. Proc. Natl. Acad. Sci. U.S.A. $109,12776-12781$.

Hsiao, E.Y., McBride, S.W., Hsien, S., Sharon, G., Hyde, E.R., McCue, T., Codelli, J.A., Chow, J., Reisman, S.E., Petrosino, J.F., 2013. Microbiota modulate behavioral and physiological abnormalities associated with neurodevelopmental disorders. Cell 155, 14511463.

Huber, D., Veinante, P., Stoop, R., 2005. Vasopressin and oxytocin excite distinct neuronal populations in the central amygdala. Science 308, 245-248.

Jacobson, L., Sapolsky, R., 1991. The role of the hippocampus in feedback regulation of the hypothalamic-pituitary-adrenocortical axis. Endocr. Rev. 12, 118-134.

Jans, J.E., Woodside, B.C., 1990. Nest temperature: effects on maternal behavior, pup development, and interactions with handling. Dev. Psychobio., 23, 519-534.

Janssen H, Ada L, Bernhardt J, McElduff P, Pollack M, Nilsson M, Spratt NJ, 2014 An enriched environment increases activity in stroke patients undergoing rehabilitation in a mixed rehabilitation unit: a pilot non-randomized controlled trial. Disabil. Rehabil 36 (3), $255-262$.

Jouda, J., Wöhr, M., del Rey, A., 2019. Immunity and ultrasonic vocalization in rodents.

Ann. N. Y. Acad. Sci. 1437, 68-82.

Kentner, A.C., Bilbo, S.D., Brown, A.S., Hsiao, E.Y., McAllister, A.K., Meyer, U., Pearce, B.D., Pletnikov, M.V., Yolken, R.H., Bauman, M.D., 2019a. Maternal immune activation: reporting guidelines to improve the rigor, reproducibility, and transparency of the model. Neuropsychopharmacology, 44, 245-258.

Kentner, A.C., Lambert, K.G., Hannan, A.J., Donaldson, S.T., 2019b. Environmental Enrichment: Enhancing Neural Plasticity, Resilience, and Repair. Front. Behav. Neurosci. 13, 75 .

Kentner, A.C., Khoury, A., Queiroz, E.L., MacRae, M., 2016. Environmental enrichment rescues the effects of early life inflammation on markers of synaptic transmission and plasticity. Brain Behav. Immun. 57, 151-160.

Kentner, A.C., Cryan, J.F., Brummelte, S., 2018a. Resilience Priming: Translational models for understanding resiliency and adaptation to early-life adversity. Dev. Psychobiol., 61, 350375.

Kentner, A.C., Scalia, S., Shin, J., Migliore, M.M., Rondón-Ortiz, A.N., 2018b. Targeted sensory enrichment interventions protect against behavioral and neuroendocrine consequences of early life stress. Psychoneuroendocrinology 98, 74-85. 
Kentner, A.C., Lima, E., Migliore, M., Shin, J., Scalia, S., 2018c. Complex environmental rearing enhances social salience and affects hippocampal corticotropin releasing hormone receptor expression in a sex-specific manner. Neuroscience, 369, 399-411.

Kesner, R.P., 2018. An analysis of dentate gyrus function (an update). Behav. Brain Res., 354, 84-91.

Kheirbek, M.A., Drew, L.J., Burghardt, N.S., Costantini, D.O., Tannenholz, L., Ahmari, S.E., Zeng, H., Fenton, A.A., Hen, R., 2013. Differential control of learning and anxiety along the dorsoventral axis of the dentate gyrus. Neuron 77, 955-968.

Kjelstrup, K.G., Tuvnes, F.A., Steffenach, H.-A., Murison, R., Moser, E.I., Moser, M.-B., 2002.

Reduced fear expression after lesions of the ventral hippocampus. Proc. Natl. Acad. Sci. U. S. A., 99, 10825-10830.

Kinsley, C., Svare, B., 1988. Prenatal stress alters maternal aggression in mice. Physiol. Behav. 42, 7-13.

Knuesel, I., Chicha, L., Britschgi, M., Schobel, S.A., Bodmer, M., Hellings, J.A., Toovey, S., Prinssen, E.P., 2014. Maternal immune activation and abnormal brain development across CNS disorders. Nat. Rev. Neurol. 10, 643.

Ko, J., 2017. Neuroanatomical substrates of rodent social behavior: the medial prefrontal cortex and its projection patterns. Front. Neural Circuits., 11, 41.

Kolb, B., Forgie, M., Gibb, R., Gorny, G., Rowntree, S., 1998. Age, experience and the changing brain. Neurosci. Biobehav. Rev. 22, 143-159.

Konkle, A.T.M., Kentner, A.C., Baker, S. L., Stewart, A., Bielajew, C., 2010. Environmental-enrichment-related variations in behavioral, biochemical, and physiologic responses to Sprague-Dawley and Long Evans rats. J. Am. Assoc. Lab Anim. Sci., 49, $427-$ 436.

Kokras, N., Hodes, G.E., Bangasser, D.A., Dalla, C. (2019). Sex differences in the hypothalamic-pituitary-adrenal axis: an obstacle to antidepressant drug development? $\mathrm{Br}$. J. Pharmacol., 176, 4090-4106.

Li, K.A., Lund, E.T., Voigt, J.-P.W., 2016. The impact of early postnatal environmental enrichment on maternal care and offspring behaviour following weaning. Behav. Processes $122,51-58$.

Li, Q., Cheung, C., Wei, R., Hui, E.S., Feldon, J., Meyer, U., Chung, S., Chua, S.E., Sham, P., Wu, E., McAlonan, G.M., 2009. Prenatal immune challenge is an environmental risk factor for brain and behavior change relevant to schizophrenia: evidence from MRI in a mouse model.

PloS one 4, e6354.

Li, W.Y., Chang, Y.C., Lee, L.,J., Lee, L.J., 2014. Prenatal infection affects the neuronal architecture and cognitive function in adult mice. Dev. Neurosci. 36, 359-370. 
Liberzon, I., Young, E.A., 1997. Effects of stress and glucocorticoids on CNS oxytocin receptor binding. Psychoneuroendocrinology 22, 411-422.

Lins, B.R., Hurtubise, J.L., Roebuck, A.J., Marks, W. N., Zabder, N.K., Scott, G.A., Greba, Q., Dawicki, W., Zhang, X., Rudulier, C.D., Gordon, J., Howland, J.G., 2018. Prospective analysis of the effects of maternal immune activation on rat cytokines during pregnancy and behavior of the male offspring relevant to schizophrenia. eNeuro, 29, ENRUO.0249-18.2018.

Lins, B.R., Marks. W.N., Zabder, N.K., Greba, Q., Howland, J.G., 2019. Maternal immune activation during pregnancy alters the behavioral profile of female offspring of Sprague Dawley rat. eNeuro, 19, ENEURO, 0437-18.2019.

Lehmann, M.L., Herkenham, M., 2011. Environmental enrichment confers stress resiliency to social defeat through an infralimbic cortex-dependent neuroanatomical pathway. J.

Neurosci. 31, 6159-6173.

Leuner, B., Gould, E., 2018. Structural plasticity and hippocampal function. Annu Rev Psychol., 61, 111-C3.

Luby, J.L., Baram, T.Z., Rogers, C.E., Barch, D.M., 2020. Neurodevelopmental Optimization after Early-Life Adversity: Cross-Species Studies to Elucidate Sensitive Periods and Brain Mechanisms to Inform Early Intervention. Trends Neurosci. 43, 744-751.

Matsuchita, H., Latt, H.M., Koga, Y., Nishiki, T., Matsui, H. (2019). Oxytocin and stress: neural mechanisms, stress related disorders, and therapeutic approaches. Neuroscience, 417, $1-10$.

Mairesse, J., Gatta, E., Reynaert, M.-L., Marrocco, J., Morley-Fletcher, S., Soichot, M., Deruyter, L., Van Camp, G., Bouwalerh, H., Fagioli, F., Pittaluga, A., Allorge, D., Nicoletti, F., Maccari, S., 2015. Activation of presynaptic oxytocin receptors enhances glutamate release in the ventral hippocampus of prenatally restraint stressed rats. Psychoneuroendocrinology, 62, 36-46.

Mak, P., Broussard, C., Vacy, K., Broadbear, J.H., 2012. Modulation of anxiety behavior in the elevated plus maze using peptidic oxytocin and vasopressin receptor ligands in the rat. J. Psychopharm. 26, 532-542.

McEwen, B.S., Magarinos, A.M., 1997. Stress effects on morphology and function of the hippocampus. Ann. N. Y. Acad. Sci. 821, 271-284.

McEwen, B.S., Bowles, N.P., Gray, J.D., Hill, M.N., Hunter, R.G., Karatsoreos, I.N., Nasca, C., 2015. Mechanisms of stress in the brain. Nat Neurosci., 18, 1353-1363.

McQuaid, R., Audet, M., Anisman, H., 2012. Environmental enrichment in male CD-1 mice promotes aggressive behaviors and elevated corticosterone and brain nor- epinephrine activity in response to a mild stressor. Stress 15, 354-360. 
McQuaid, R.J., Audet, M.C., Jacobson-Pick, S., Anisman, H., 2013. Environmental enrichment influences brain cytokine variations elicited by social defeat in mice. Psychoneuroendocrinology 38, 987-996.

McQuaid, R.J., Dunn, R., Jacobson-Pick, S., Anisman, H., Audet, M.-C. (2018). Postweaning environmental enrichment in male CD-1 mice: impact on social behaivors, corticosterone levels and prefrontal cytokine expression in adulthood. Front. Behav. Neurosci. 12,145 .

Miles, J., Shevlin, M., 2001. Applying Regression and Correlation: A Guide for Students and Researchers, first ed. (London).

Moncek F, Duncko B, Johansson B, Zezova D. 2004. Effect of environmental enrichment on stress related systems in rats. J Neuroendocrinol 16:423-431.

Meyer, U., Nyffeler, M., Engler, A., Urwyler, A., Schedlowski, M., Knuesel, I., Yee, B.K., Feldon, J., 2006. The time of prenatal immune challenge determines the specificity of inflammation-mediated brain and behavioral pathology. J. Neurosci. 26, 4752-4762.

Meyer-Lindenberg, A., 2008. Impact of prosocial neuropeptides on human brain function. Prog. Brain Res. 170, 463-470.

Morgan C, Novak I, Dale RC, Guzzetta A, Badawi N, 2014 GAME (Goals-Activity-Motor Enrichment): protocol of a single blind randomised controlled trial of motor training, parent education and environmental enrichment for infants at high risk of cerebral palsy. BMC Neurol.

14(1), 203 10.1186/s12883-014-0203-2.

Morgan, C., Novak, I., Dale, R. C., \& Badawi, N., 2015. Optimising motor learning in infants at high risk of cerebral palsy: A pilot study. BMC Pediatrics, 15, 30

Mueller, F.S., Richetto, J., Hayes, L.N., Zambon, A., Pollak, D.D., Sawa, A., Meyer, U., Weber-Stadlbauer, U., 2019. Influence of poly (I: C) variability on thermoregulation, immune

responses and pregnancy outcomes in mouse models of maternal immune activation. Brain Behav. Immun. 80, 406-418.

Müller, M.B., Zimmermann, S., Sillaber, I., Hagemeyer, T.P., Deussing, J.M., Timpl, P., Kormann, M.S., Droste, S.K., Kühn, R., Reul, J.M., 2003. Limbic corticotropin-releasing hormone receptor 1 mediates anxiety-related behavior and hormonal adaptation to stress. Nat. Neurosci. 6, 1100-1107.

Noonan, L.R., Caldwell, J.D., Li, L., Walker, C.H., Pedersen, C.A., Mason, G.A., 1994. Neonatal stress transiently alters the development of hippocampal oxytocin receptors. Dev. Brain Res. 80, 115-120.

Nicholson, A., Malcolm, R.D., Russ, P.L., Cough, K., Touma, C., Palme, R., Wiles, M.V., 2009. The response of C57BL/6J and BALB/cJ mice to increased housing density. J. Am. Associ. Lab Anim. Sci., 48, 740-753. 
Núñez Estevez, K., Rondón-Ortiz, A., Nguyen, J., Kentner, A.C., 2020. Environmental influences on placental programming and offspring outcomes following maternal immune activation. Brain Behav.Immun., 83, 44-55.

Ozawa, K., Hashimoto, K., Kishimoto, T., Shimizu, E., Ishikura, H., Iyo, M., 2006. Immune activation during pregnancy in mice leads to dopaminergic hyperfunction and cognitive impairment in the offspring: a neurodevelopmental animal model of schizophrenia. Biol. Psychiatry 59, 546-554.

Padilla-Coreano, N., Bolkan, S.S., Pierce, G.M., Blackman, D.R., Hardin, W.D., GarciaGarcia,

A.L., Spellman, T.J., Gordon, J.A., 2016. Direct ventral hippocampal-prefrontal input is required for anxiety-related neural activity and behavior. Neuron 89, 857-866.

Pfaff, D., Barbas, H., 2019. Mechanisms for the approach/avoidance decision applied to autism. Trends Neurosci. 42, 448-457.

Piontkewitz, Y., Arad, M., Weiner, I., 2011. Abnormal trajectories of neurodevelopment and behavior following in utero insult in the rat. Biol. Psychiatry 70, 842-851.

Quiñones-Jenab, V., Jenab, S., Ogawa, S., Adan, R.A.M., Burbach, J.P.H., Pfaff, D.W., 1997. Effects of estrogen on oxytocin receptor messenger ribonucleic acid expression in the uterus, pituitary, and forebrain of the female rat. Neuroendocrinology, 65, 9-17.

Radke, S., Güths, F., André, J.A., Müller, B.W., de Bruijn, E.R., 2014. In action or inaction? Social approach-avoidance tendencies in major depression. Psychiatry Res. 219, 513-517.

Rilling, J.K., DeMarco, A.C., Hackett, P.D., Chen, X., Gautam, P., Stair, S., Haroon, E., Thompson, R., Ditzen, B., Patel, R., 2014. Sex differences in the neural and behavioral response to intranasal oxytocin and vasopressin during human social interaction.

Psychoneuroendocrinology 39, 237-248.

Rojas-Carvajal, M., Fornaguera, J., Mora-Gallegos, A.m Brenes, J.C., 2018. Testing experience and environmental enrichment potentiated open-field habituation and grooming behavior in rats. Anim Behav., 137, 1-11.

Ronovsky, M., Berger, S., Zambon, A., Reisinger, S.N., Horvath, O., Pollak, A., Lindtner, C., Berger, A., Pollak, D.D., 2017. Maternal immune activation transgenerationally modulates maternal care and offspring depression-like behavior. Brain Behav. Immun. 63, 127-136.

Rosbergen, I.C., Grimley, R.S., Hayward, K.S., Walker, K.C., Rowley, D., Campbell, A.M., McGufficke, S., Robertson, S.T., Trinder, J., Janssen, H., 2017. Embedding an enriched environment in an acute stroke unit increases activity in people with stroke: a controlled before-after pilot study. Clin. Rehabil. 31, 1516-1528.

Sale, A., Putignano, E., Cancedda, L., Landi, S., Cirulli, F., Berardi, N., Maffei, L., 2004. Enriched environment and acceleration of visual system development. Neuropharmacology 47, 649-660. 
Schneider CA, Rasband WS, Eliceiri KW., 2012. NIH Image to ImageJ: 25 years of image analysis. Nat Methods, 9, 671-675. doi: 10.1038/nmeth.2089.

Schwendener, S., Meyer, U., Feldon, J., 2009. Deficient maternal care resulting from immunological stress during pregnancy is associated with a sex-dependent enhancement of conditioned fear in the offspring. J Neurodev. Disord., 1, 15-32.

Scarborough, J., Mueller, F., Arban, R., Dorner-Ciossek, C., Weber-Stadlbauer, U., Rosenbrock, H., Meyer, U., Richetto, J., 2020. Preclinical validation of the micropipetteguided drug administration (MDA) method in the maternal immune activation model of neurodevelopmental disorders. Brain Behav. Immun., 88, 461-470.

Schwartzer, J., Careaga, M., Onore, C., Rushakoff, J., Berman, R.F., Ashwood, P., 2013. Maternal immune activation and strain specific interactions in the development of autismlike behaviors in mice. Transl. Psychiatry 3, e240-e240.

Selye H., 1956. The stress of life. New York (NY): McGraw-Hill Book Company

Shi, L., Fatemi, S.H., Sidwell, R.W., Patterson, P.H., 2003. Maternal influenza infection causes marked behavioral and pharmacological changes in the offspring. J. Neurosci. 23, 297-302.

Skelton KH, Nemeroff CB, Knight DL, Owens MJ., 2000. Chronic administration of the Triazolobenzodiazepine Alprazolam produces opposite effects on corticotropin-releasing factor and urocortin neuronal systems. J Neurosci 20:1240-1248.

Smith, B.L., Lyons, C.E., Correa, F.G., Benoit, S.C., Myers, B., Solomon, M.B., Herman, J.P., 2017. Behavioral and physiological consequences of enrichment loss in rats. Psychoneuroendocrinology 77, 37-46.

Smith, S.E., Li, J., Garbett, K., Mirnics, K., Patterson, P.H., 2007. Maternal immune activation alters fetal brain development through interleukin-6. J. Neurosci. 27, 10695-10702.

Sorge, R.E., Mapplebeck, J.C.S., Rosen, S., Beggs, S., Taves, S., Alexander, J.K., Martin, L.J.,

Austin, J-S., Sotocinal, S.G., Chen, D., Yang, M., Qui Shi, X., Huang, H., Pillon, N.J., Bilan, P.J., Tu, Y., Klip, A., Ji, R-R., Salter, M.W., Mogil, J.S. (2015). Different immune cells mediate mechanical pain hyersensitivity in male and female mice. Nat. Neurosci., 18, 1081-1083.

Sørensen, H.J., Mortensen, E.L., Reinisch, J.M., Mednick, S.A., 2008. Association between prenatal exposure to bacterial infection and risk of schizophrenia. Schizophr. Bull. 35, 631637.

Sturman, O., Germain, P.-L., Bohacek, J., 2018. Exploratory rearing: a context-and stresssensitive behavior recorded in the open-field test. Stress 21, 443-452.

Strzelewicz, AR., Ordoñes Sanchez, E., Rondón-Ortiz, AN., Raneri, A., Famularo, ST., Bangasser, DA., Kentner, AC., 2019. Access to a high resource environment protects against 
accelerated maturation following early life stress: A translational animal model of high, medium and low security settings. Horm. Behav., 111, 46-59.

Symonds, C.S., McKie, S., Elliott, R., Deakin, J.F.W., Anderson, I.M., 2012. Detection of the acute effects of hydrocortisone in the hippocampus using pharmacological fMRI. European Neuropsychopharmacol., 22, 867-874.

Van Dellen, A., Blakemore, C., Deacon, R., York, D., Hannan, A.J., 2000. Delaying the onset of Huntington's in mice. Nature 404, 721-722.

Van Praag, H., Kempermann, G., Gage, F.H., 2000. Neural consequences of enviromental enrichment. Nat. Rev. Neurosci. 1, 191.

Vivinetto, A.L., Suarez, M.M., Rivarola, M. A., 2013. Neurobiological effects of neonatal maternal separation and post-weaning environmental enrichment. Behav. Brain Res., 240, $110-118$.

Walsh, J.J., Christoffel, D.J., Wu, X., Pomrenze, M.B., Malenka, R.C., 2020. Dissecting neural mechanisms of prosocial behaviors. Curr. Opin. Neurol., 68, 9-14.

Wang X-D, Labermaier C, Holsboer F, Wurst W, Deussing JM, Muller MB, Schmidt MV., 2012. Early-life stress-induced anxiety-related behavior in adult mice partially required forebrain corticotropin- releasing hormones receptor 1. Eur J Neurosci 36:2360-2367.

Weber, E.M., Olsson, I.A.S., 2008. Maternal behaviour in Mus musculus sp.: an ethological review. Appl. Anim. Behav. Sci. 114, 1-22

Weber-Stadlbauer, U., Richetto, J., Zwamborn, R. J., Slieker, R.C., Meyer, U., 2020. Transgenerational modification of dopaminergic dysfunctions induced by maternal immune activation. Neuropsychopharmacology, 46, 404-412.

Weeden, C.S., Roberts, J.M., Kamm, A.M., Kesner, R.P., 2015. The role of the ventral dentate

gyrus in anxiety-based behaviors. Neurobiol. Learn. Mem. 118, 143-149.

Welberg, L., Thrivikraman, K.V., Plotsky, P.M., 2006. Combined pre- and postnatal environmental enrichment programs the HPA axis differentially in male and female rats. Psychoneuroendocrinology 31 (5), 553-564.

Williams AV, Duque-Wilckens N, Ramos-Maciel S, Campi KL, Bhela SK, Xu CK, Jackson K, Chini B, Pesavento PA, Trainor B.C., 2020. Social approach and social vigilance are differentially regulated by oxytocin receptors in the nucleus accumbens. Neuropsychopharmacology, 45, 1423-1430. doi: 10.1038/s41386-020-0657-4.

Woo CC, Donnelly JH, Steinberg-Epstein R, Leon M, 2015 Environmental enrichment as a therapy for autism: a clinical trial replication and extension. Behav. Neurosci 129 (4), 412422.

Zhang, T.-Y., Keown, C.L., Wen, X., Li, J., Vousden, D.A., Anacker, C., Bhattacharyya, U., Ryan, R., Diorio, J., O’Toole, N., Lerch, J.P., Mukamel, E.A., Meaney, M.J., 2018. 
Environmental enrichment increases transcriptional and epigenetic differentiation between mouse dorsal and ventral dentate gyrus. Nat Comm., 19, 298.

Zeleznikow-Johnston, A., Burrows, E.L., Renoir, T., Hannan, A.J., 2017. Environmental enrichment enhances cognitive flexibility in C57BL/6 mice on a touchscreen reversal learning task. Neuropharmacology 117, 219-226.

Zhao, X., Rondón-Ortiz, A.N., Lima, E.P., Puracchio, M., Roderick, R.C., Kentner, A.C., 2020. Therapeutic efficacy of environmental enrichment on behavioral, endocrine, and synaptic alterations in an animal model of maternal immune activation. Brain Behav. Immun. -Health., 100043.

Zuckerman, L., Rehavi, M., Nachman, R., Weiner, I., 2003. Immune activation during pregnancy in rats leads to a postpubertal emergence of disrupted latent inhibition, dopaminergic hyperfunction, and altered limbic morphology in the offspring: a novel neurodevelopmental model of schizophrenia. Neuropsychopharmacology 28, 1778. 
Poly (I:C) Validation:

Body Weight Assessment
Maternal Nest Quality Assessment
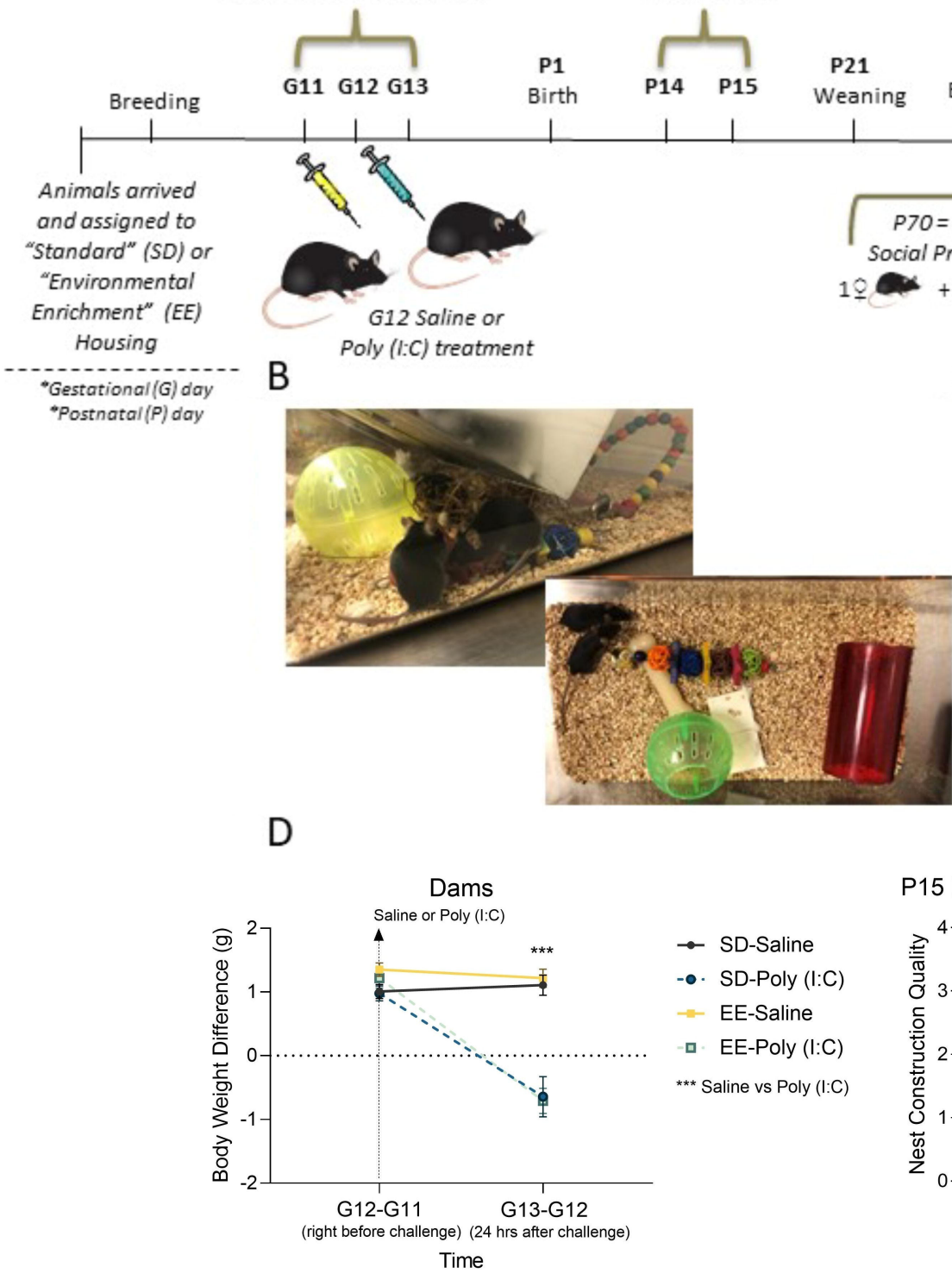

Animals arrived

and assigned to
D

\section{Housing}

Gestational (G) day

estational(G) day

E $\rightarrow$ SD-Saline

-๑. SD-Poly (I:C)

-- EE-Saline

-․ EE-Poly (I:C)

*** Saline vs Poly (I:C)
P85

Behavior \&

P70

Behavior issue Collection

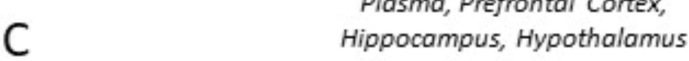

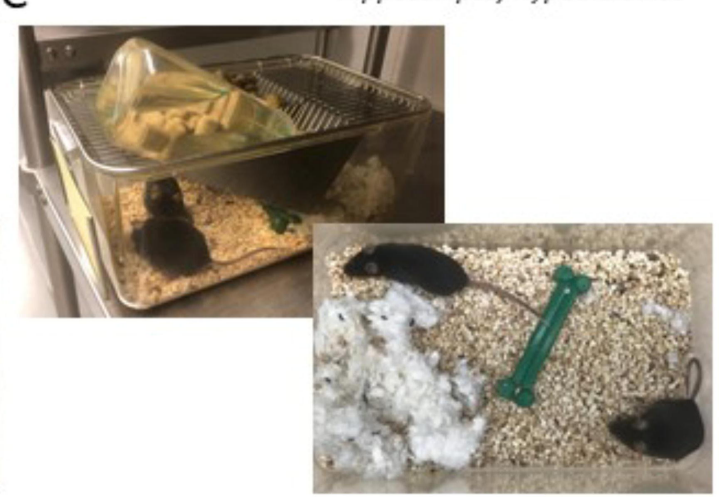

P15 Nest Construction Quality

- SD-Saline

- SD-Poly (I:C)

II EE-Saline

- EE-Poly (I:C)

* different from SD-Saline

\# different from EE-Poly (I:C)

Figure 1 
A

D

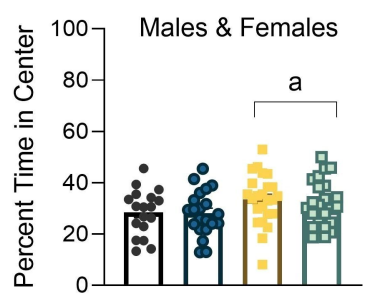

B

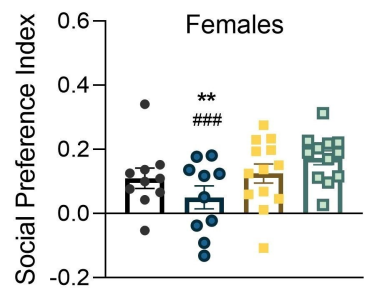

C

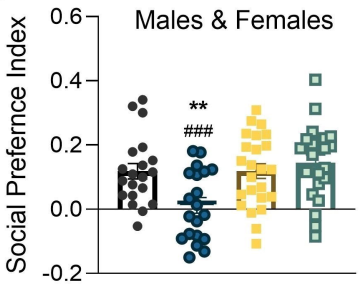

$\mathrm{E}$

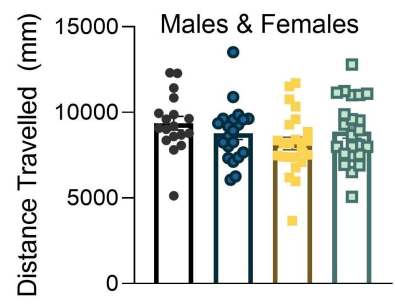

$\mathrm{F}$

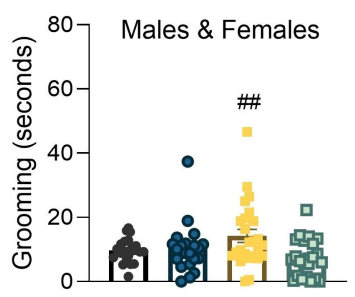

J

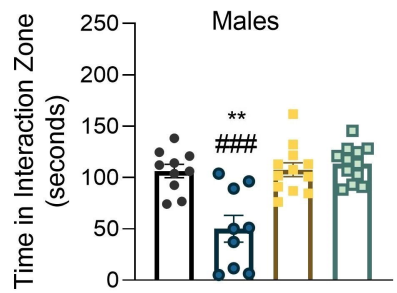

G

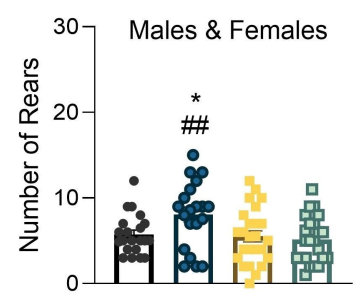

$\mathrm{H}$

I

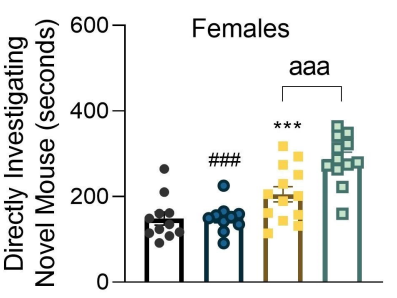

- SD-Saline

- SD-Poly (I:C)

EE-Saline

ㅁ EE-Poly (I:C)

* different from SD-Saline

\# different from EE-Poly (I:C)

Figure 2
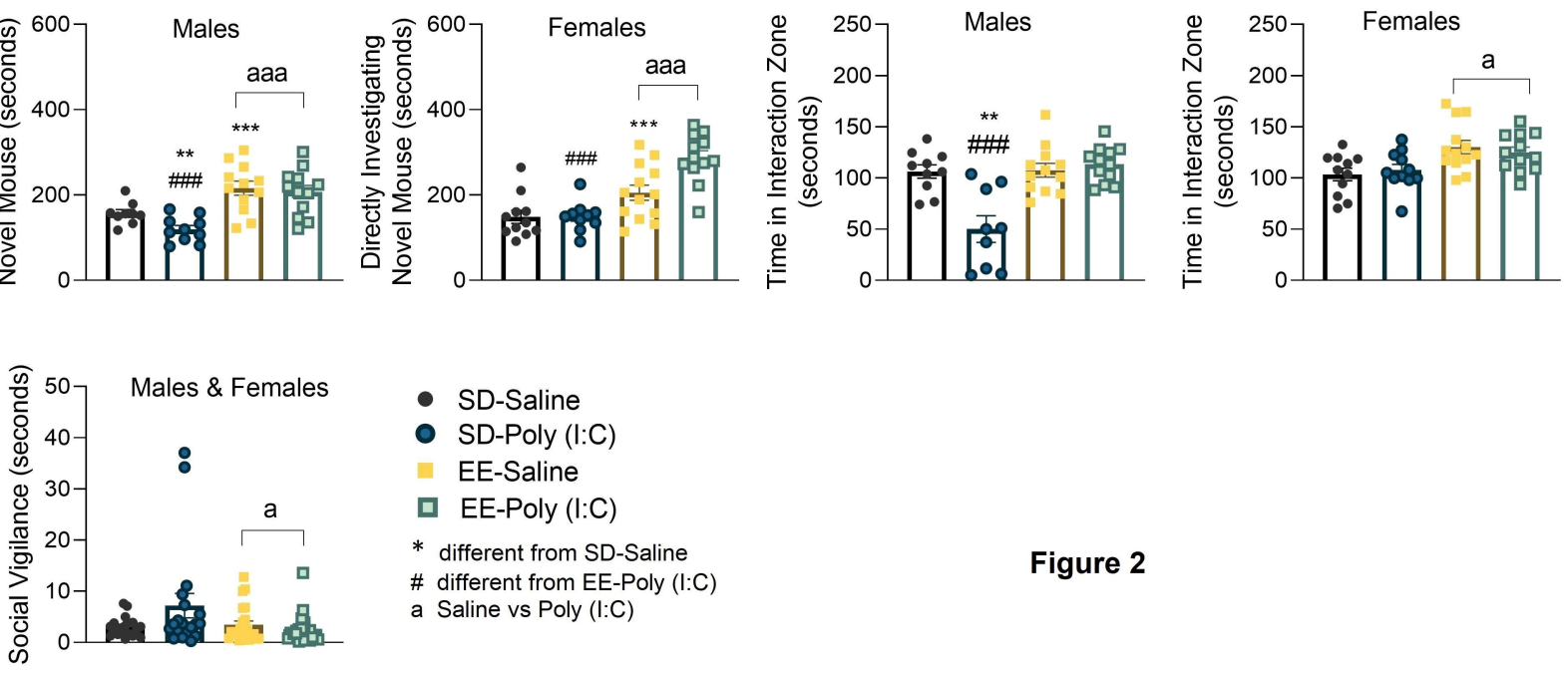

a Saline vs Poly $(\mathrm{I}: \mathrm{C})$ 
bioRaxiv preprint doi: https://doi.org/10.1101/2081.01.21.427695; this version posted February 28, 2021. The copyright holder for this preprint (which was not certified by peer review) is the author/funder, who has granted bioRxiv a license to display the preprint in perpetuity. It is made

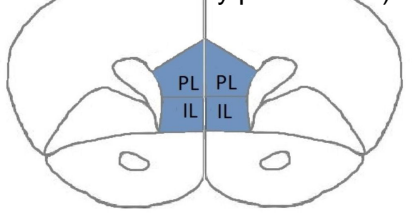

C

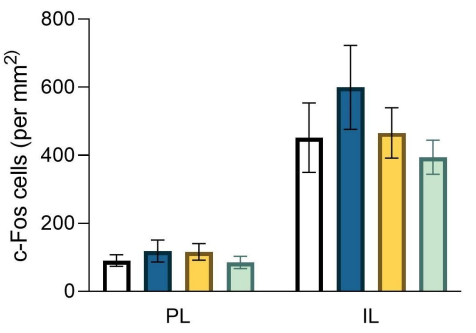
available under aCG BKNC-ND 4. Onternational license SD-Saline
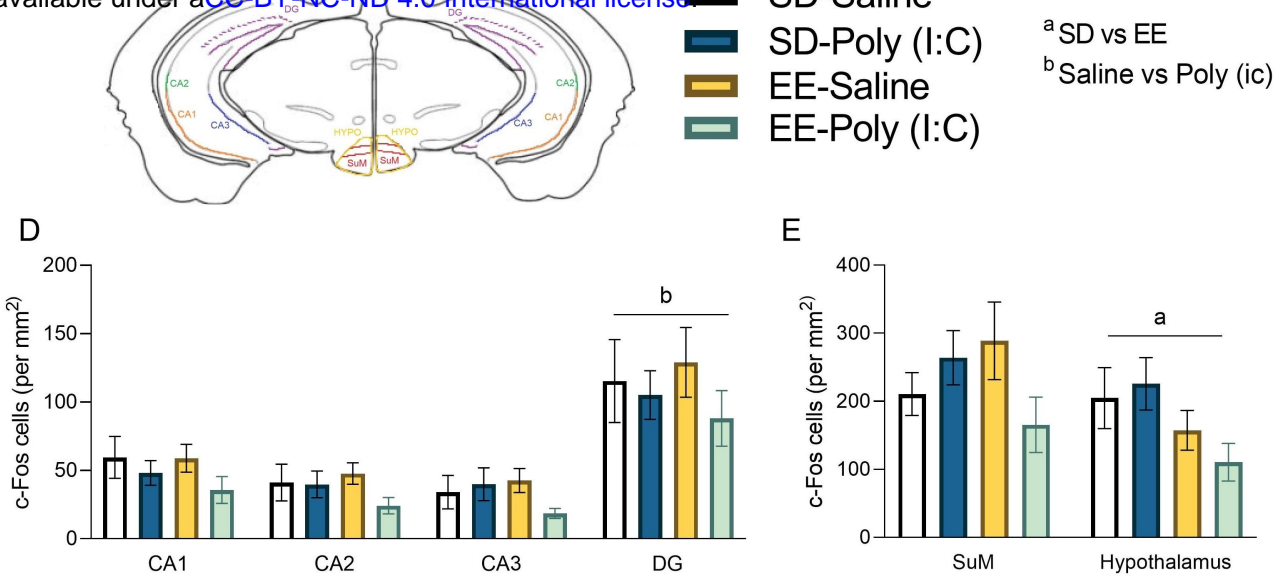

$\mathrm{F}$

SD-Saline

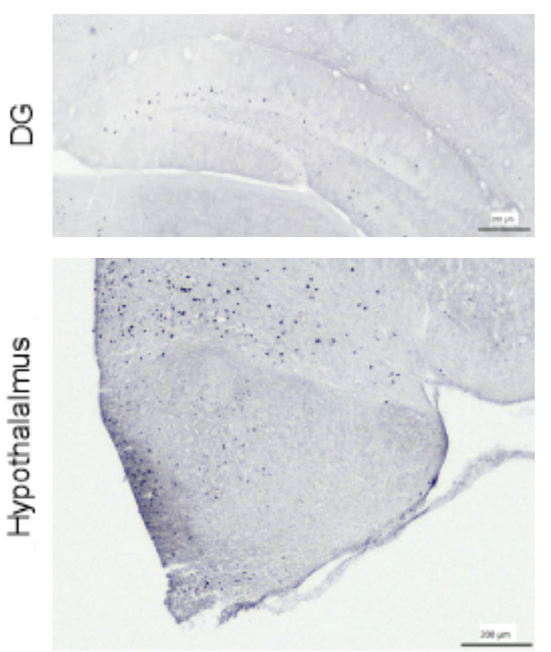

G

SD

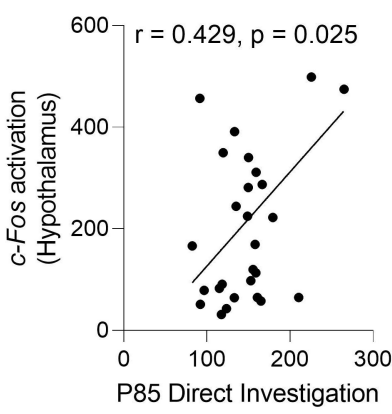

EE

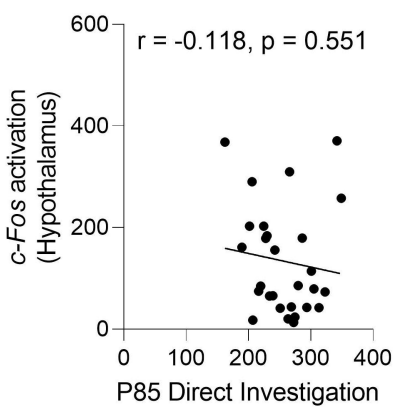

Figure 3
SD-Poly (I:C)

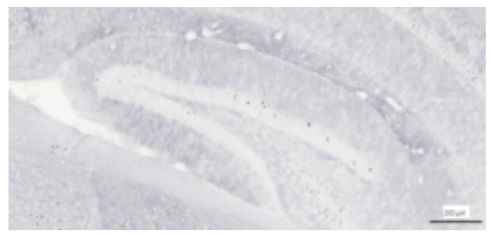

$\mathrm{H}$

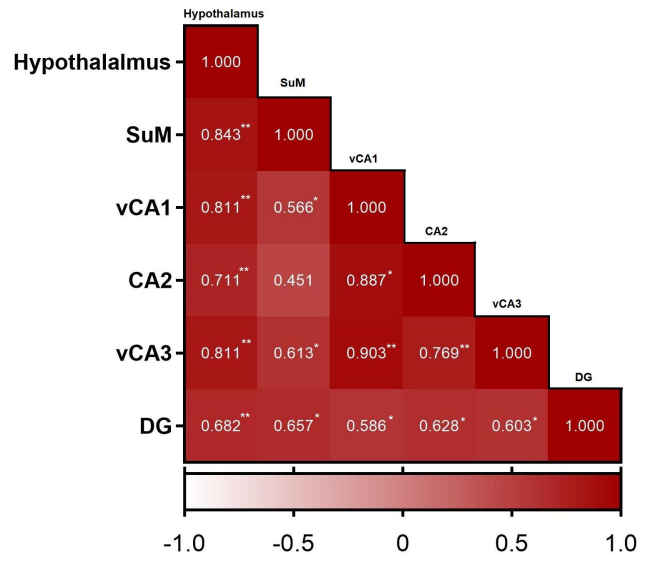

EE-Saline

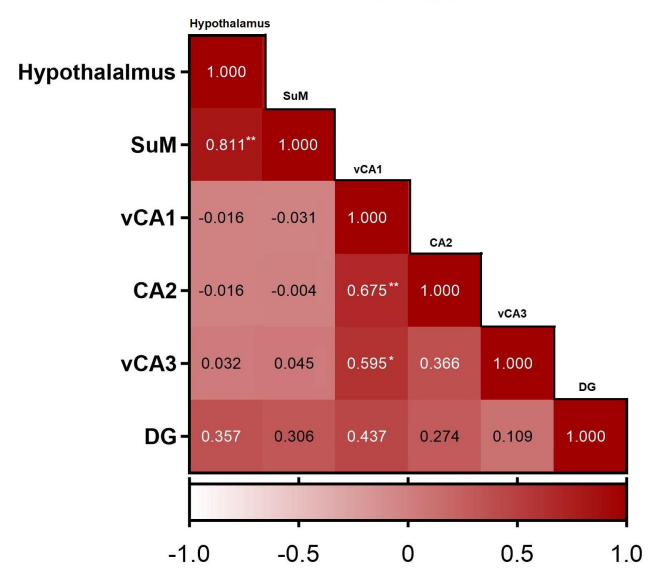

EE-Saline
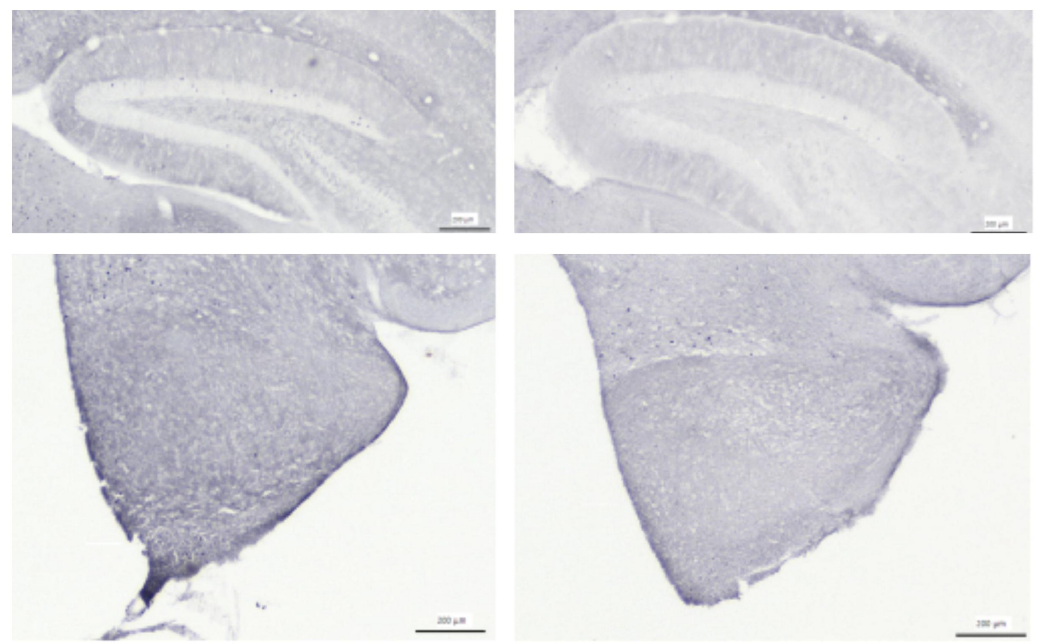

SD-Poly (I:C)

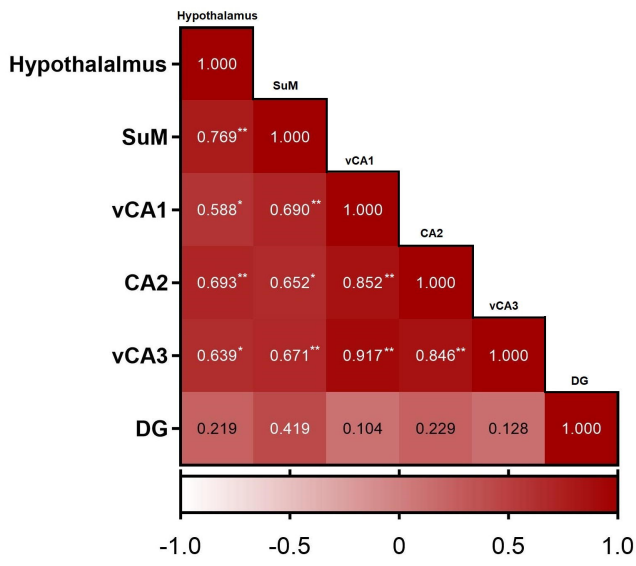

EE-Poly (I:C)

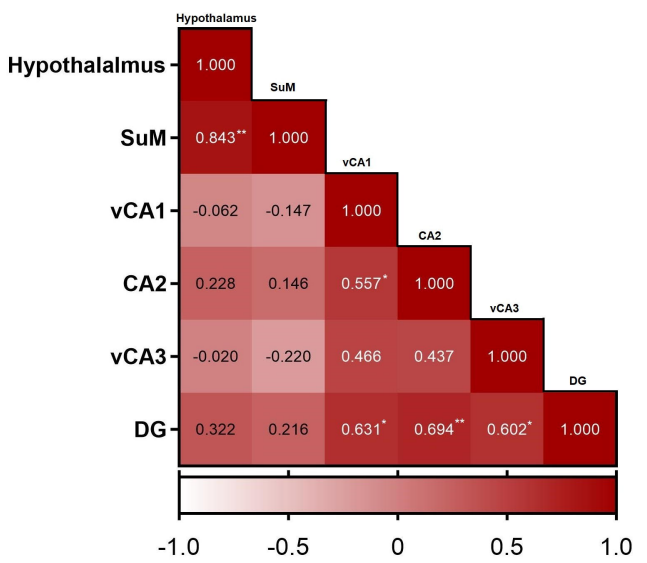


A

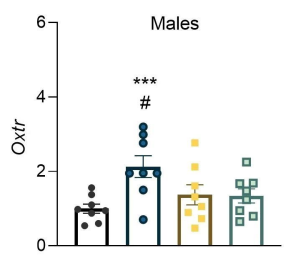

B

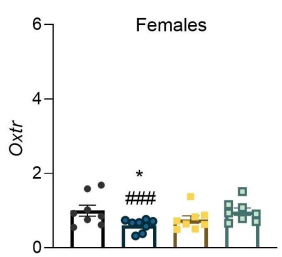

C

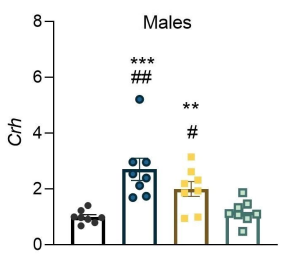

D

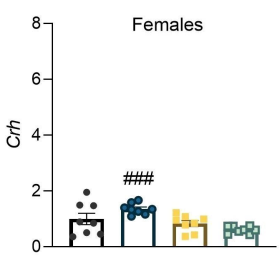

E

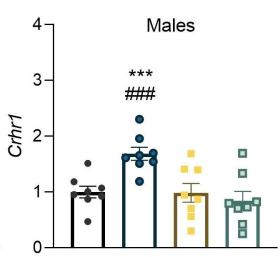

F

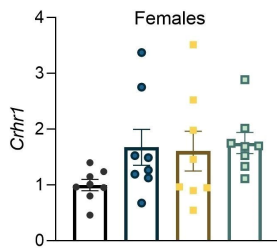

G

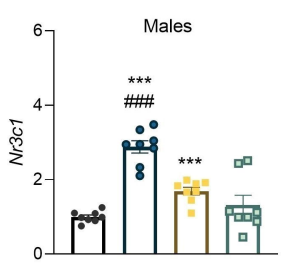

K

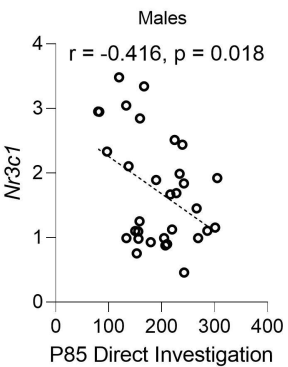

P

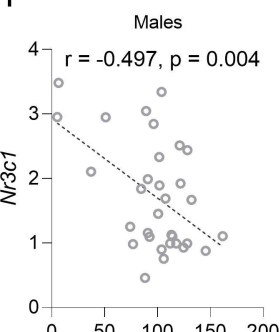

U

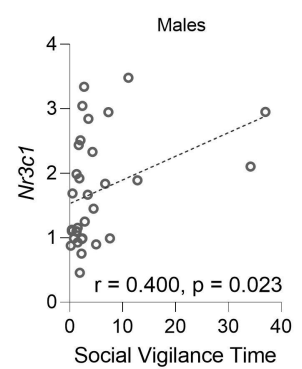

$\mathrm{H}$

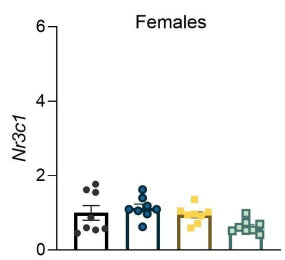

L

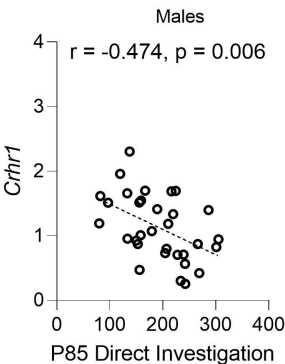

Q

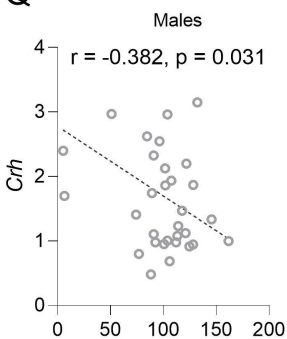

I

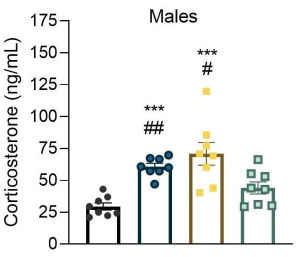

M

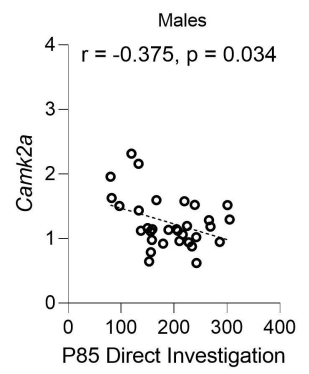

R

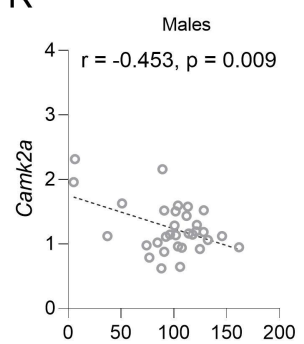

P85 Time in Interaction Zone

W

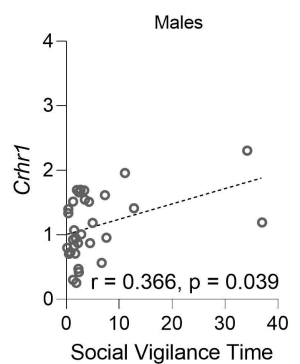

$\mathrm{J}$

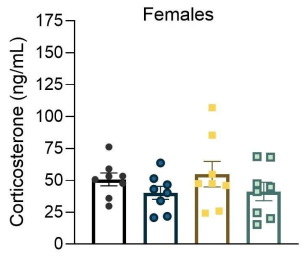

- SD-Saline * different from SD-Saline

- SD-Poly (I:C) \# different from EE-Poly (I:C)

$\mathrm{N}$

0
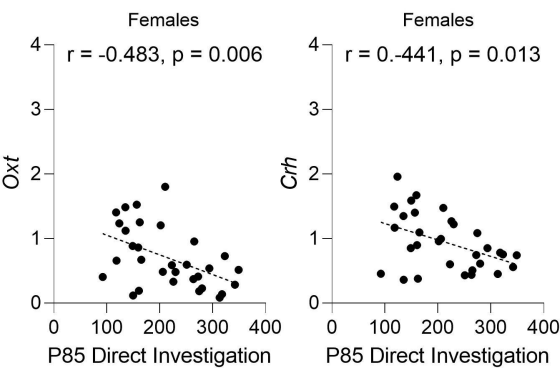

$S$

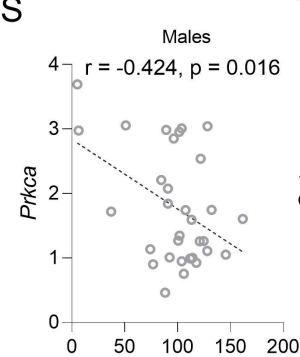

$T$

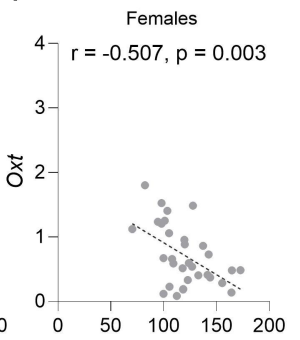

P85 Time in Interaction Zone

P85 Time in Interaction Zone

$X$

$Y$
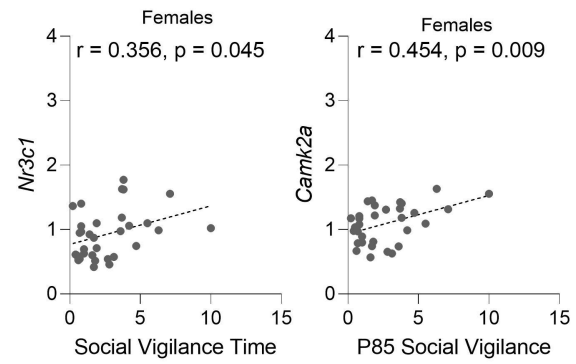

Figure 4 